\title{
Cyclic RGD Peptidomimetics Containing Bifunctional Diketopiperazine Scaffolds as New Potent Integrin Ligands
}

\author{
Mattia Marchini, ${ }^{[a]}$ Michele Mingozzi, ${ }^{[a]}$ Raffaele Colombo, ${ }^{[a]}$ Ileana Guzzetti, ${ }^{[a]}$ \\ Laura Belvisi, ${ }^{[a]}$ Francesca Vasile, ${ }^{[a]}$ Donatella Potenza, ${ }^{[a]}$ Umberto Piarulli, ${ }^{[b]}$ \\ Daniela Arosio, ${ }^{[c]}$ and Cesare Gennari*[a]
}

\begin{abstract}
The synthesis of eight bifunctional diketopiperazine (DKP) scaffolds is described; these were formally derived from 2,3-diaminopropionic acid and aspartic acid (DKP-1-DKP-7) or glutamic acid (DKP-8) and feature an amine and a carboxylic acid functional group. The scaffolds differ in the configuration at the two stereocenters and the substitution at the diketopiperazinic nitrogen atoms. The bifunctional diketopiperazines were introduced into eight cyclic peptidomimetics containing the Arg-Gly-Asp (RGD) sequence. The resulting RGD peptidomimetics were screened for their ability to inhibit biotinylated vitronectin binding to
\end{abstract}

the purified integrins $\alpha_{\mathrm{v}} \beta_{3}$ and $\alpha_{\mathrm{v}} \beta_{5}$, which are involved in tumor angiogenesis. Nanomolar $\mathrm{IC}_{50}$ values were obtained for the RGD peptidomimetics derived from trans DKP scaffolds (DKP-2-DKP-8). Conformational studies of the cyclic RGD peptidomimetics by ${ }^{1} \mathrm{H}$ NMR spectroscopy experiments (VT-NMR and NOESY spectroscopy) in aqueous solution and Monte Carlo/Stochastic Dynamics (MC/SD) simulations revealed that the

Keywords: conformation analysis . diketopiperazines $\cdot$ molecular modeling $\cdot$ peptides $\cdot$ peptidomimetics

\begin{abstract}
highest affinity ligands display well-defined preferred conformations featuring intramolecular hydrogen-bonded turn motifs and an extended arrangement of the RGD sequence [C $\beta(\mathrm{Arg})$ $\mathrm{C} \beta$ (Asp) average distance $\geq 8.8 \AA]$. Docking studies were performed, starting from the representative conformations obtained from the MC/SD simulations and taking as a reference model the crystal structure of the extracellular segment of integrin $\alpha_{v} \beta_{3}$ complexed with the cyclic pentapeptide, Cilengitide. The highest affinity ligands produced top-ranked poses conserving all the important interactions of the X-ray complex.
\end{abstract}

\section{Introduction}

Integrins are a large family of transmembrane heterodimeric receptors that, once bound to extracellular matrix proteins, regulate a variety of cellular processes. ${ }^{[1]}$ As a consequence of their role in important physiological phenomena, integrin defects have been implicated in many common diseases.

[a] M. Marchini, M. Mingozzi, R. Colombo, I. Guzzetti, Dr. L. Belvisi, Dr. F. Vasile, Dr. D. Potenza, Prof. Dr. C. Gennari

Università degli Studi di Milano

Dipartimento di Chimica Organica e Industriale

Via Venezian, 21, I-20133, Milan (Italy)

Fax: (+39) 0250314072

E-mail: laura.belvisi@unimi.it cesare.gennari@unimi.it

[b] Prof. Dr. U. Piarulli

Università degli Studi dell'Insubria

Dipartimento di Scienza e Alta Tecnologia

Via Valleggio 11, I-22100, Como (Italy)

Fax: (+39) 0312386449

E-mail: umberto.piarulli@uninsubria.it

[c] Dr. D. Arosio

CNR, Istituto di Scienze e Tecnologie Molecolari (ISTM)

Via Venezian, 21, I-20133, Milan (Italy)

Supporting information for this article is available on the WWW under http://dx.doi.org/10.1002/chem.201200457.
Hence, it is not surprising that some integrins have become attractive targets for pharmacological intervention in a number of pathological conditions. ${ }^{[2]}$ The observation that $\alpha_{\mathrm{V}} \beta_{3}, \alpha_{\mathrm{V}} \beta_{5}$ and $\alpha_{5} \beta_{1}$ integrin subtypes are essential for tumor angiogenesis and can be successfully inhibited by small-molecule ligands has turned them into the focus of cancer research. $^{[3]}$

Across their extracellular $\alpha / \beta$ subunit interface containing the metal ion-dependent adhesion site (MIDAS), integrins recognize and bind protein ligands through contiguous tripeptide sequences, the majority of which are present within flexible loop regions and contain an acidic residue. ${ }^{[4]}$ Several integrins, including $\alpha_{5} \beta_{1}$ and $\alpha_{V}$ integrins, recognize ArgGly-Asp (RGD) sequences in endogenous ligands. The context of the ligand RGD sequence (flanking residues, three dimensional presentation) and individual features of the integrin binding pockets determine the recognition specificity and efficacy. A major breakthrough for understanding this interaction at a molecular level came in 2002 when the Xray structure of the complex of integrin $\alpha_{V} \beta_{3}$ with cyclo[Arg-Gly-Asp-D-Phe-N(Me)-Val] (Cilengitide) was revealed. ${ }^{[5]}$ This potent $\alpha_{\mathrm{V}} \beta_{3}$ ligand was developed by Kessler and co-workers (Figure 1), ${ }^{[6,7]}$ and is currently in phase III clinical trials as an angiogenesis inhibitor for patients with glioblastoma multiforme. ${ }^{[8]}$ The high activity and selectivity of this derivative has been attributed to an extended confor- 
<smiles>CC(C)[C@H](C(=O)N[C@@H](CCCN=C(N)N)C(=O)NCC(=O)N[C@@H](CC(=O)O)C(=O)NC(Cc1ccccc1)Cc1ccccc1)N(C)C(=O)[C@H](C)C(=O)O</smiles>

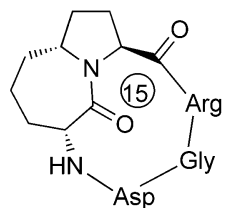

ST-1646 (Scolastico and co-workers)
Cilengitide (Kessler and co-workers)

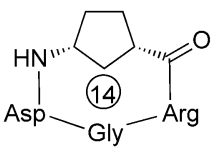

(Casiraghi and co-workers)

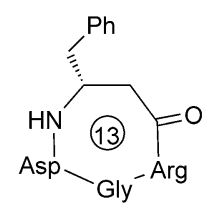

(Sewald and co-workers)

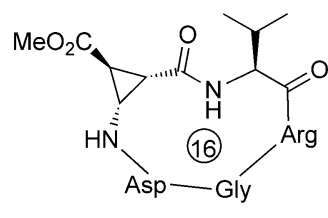

(Sewald, Reiser and co-workers)
Figure 1. Potent $\alpha_{V} \beta_{3}$ ligands.

mation of the RGD motif displaying a distance of about $9 \AA$ between the $\mathrm{C}_{\beta}$ atoms of Asp and Arg. ${ }^{[5]}$

These observations prompted many other research groups to investigate the use of conformationally constrained cyclic RGD peptides and peptidomimetics as active and selective integrin ligands, encompassing a wide variety of rigid scaffolds and featuring 13-, 14-, 15- and 16-membered rings (Figure 1). ${ }^{[9]}$ Among the successful approaches, we would like to mention the $\gamma$-amino acid RGD peptidomimetics containing a $\gamma$-aminocyclopentane carboxylic acid or a 4aminoproline residue (14-membered ring), ${ }^{[10]}$ the azabicyclic lactam RGD peptidomimetics (15-membered ring, with the scaffold mimicking a constrained dipeptide, e.g., ST1646), ${ }^{[11]}$ and the $\beta$-amino acid RGD peptidomimetics, embodying $\beta^{3}$ homoamino acids ${ }^{[12]}$ (13-membered ring) or a cis- $\beta$-aminocyclopropane carboxylic acid (16-membered ring). ${ }^{[13]} \mathrm{Up}$ to now, a large number of linear or cyclic peptidic and peptidomimetic ligands have been developed, which are all related to the common recognition motif $\mathrm{RGD}^{[14]}$ and a few potent ligands are presently in different stages of clinical trials for cancer therapy. Notwithstanding these recent achievements, the discovery of new ligands displaying high activity and selectivity together with an optimal pharmacological profile still remains a challenge. Moreover, a clear-cut explanation of the geometrical requirements of the RGD peptidomimetics in their interaction with the different integrins is still lacking (the above-mentioned X-ray structural information suffers from a rather coarse resolution).$^{[5]}$

New bifunctional diketopiperazine (DKP) scaffolds [DKP-1 (cis) and DKP-2 (trans); Figure 2] were recently developed, which are formally derived from aspartic acid and 2,3-diaminopropionic acid and bear a carboxylic acid and an amino functionality. ${ }^{[15]}$ These bifunctional diketopiperazines were introduced into the 17-membered cyclic RGD peptidomimetics cyclo-[DKP-1-RGD] (9) and cyclo-[DKP-2-RGD] (10; Figure 3), and their conformations and biological activities were investigated. ${ }^{[16]}$ Cyclo-[DKP-2-RGD] (10) effec-

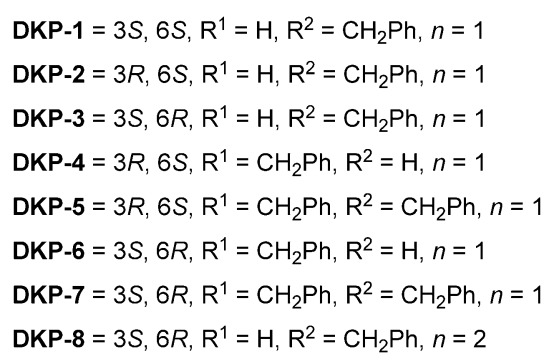

Figure 2. Bifunctional DKP scaffolds.

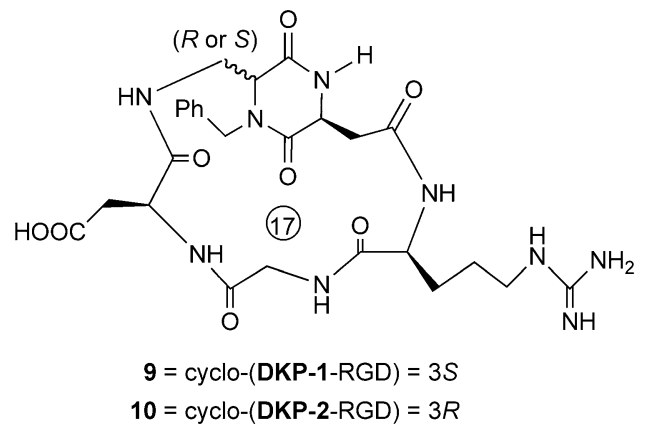

Figure 3. Cyclic RGD peptidomimetics containing bifunctional DKP scaffolds

tively inhibited biotinylated vitronectin binding to the purified $\alpha_{v} \beta_{3}$ receptor at low nanomolar concentration, whereas cyclo-[DKP-1-RGD] (9) required a micromolar concentration. ${ }^{[16]}$ These results were interpreted in terms of a more extended RGD sequence imparted by the trans geometry of the diketopiperazine scaffold (DKP-2) to give rise to a better pre-organization of peptidomimetic $\mathbf{1 0}$ for binding to the integrin receptors. These observations prompted us to investigate the structural elements of the bifunctional diketopiperazine scaffold that are able to influence and possibly improve the binding of the cyclo-[DKP-RGD] peptidomimetics.

Herein we present a full account of our investigations and report: 1) the synthesis of a number of cyclic RGD peptidomimetics containing various diketopiperazine scaffolds with different stereochemistry and substitution at the piperazinic nitrogen atoms; 2) the ability of the cyclic RGD peptidomimetics to compete with biotinylated vitronectin for binding to the purified $\alpha_{v} \beta_{3}$ and $\alpha_{v} \beta_{5}$ receptors; 3) conformational studies of the cyclic RGD peptidomimetics in aqueous solution by ${ }^{1} \mathrm{H}$ NMR spectroscopy experiments; 4) conformational studies of the cyclic RGD peptidomimetics by Monte Carlo/Stochastic Dynamics (MC/SD) simulations; 5) docking studies of the cyclic RGD peptidomimetics in the crystal structure of the $\alpha_{v} \beta_{3}$ binding site.

\section{Results and Discussion}

Synthesis of the diketopiperazine scaffolds and cyclic RGD peptidomimetics: A collection of eight diketopiperazines 
(DKP-1-DKP-8) was synthesized, and their stereochemistry and substitution patterns were varied (Figure 2). In particular the scaffolds differ in: 1) the relative stereochemistry, namely cis (DKP-1) or trans (DKP-2-DKP-8); 2) the absolute stereochemistry of the trans scaffolds $[3 R, 6 S$ (DKP-2, DKP-4, DKP-5) or $3 S, 6 R$ (DKP-3, DKP-6, DKP-7, DKP8)]; 3) the substitution at the endocyclic nitrogen atoms, which can be either hydrogen or benzyl (DKP-2, DKP-3, DKP-4, DKP-6, DKP-8) or dibenzyl (DKP-5, DKP-7); 4) the length of the side-arm bearing the carboxylic group, which can be either carboxymethyl (DKP-1-DKP-7) or carboxyethyl (DKP-8).

Two different strategies were devised for the synthesis of DKP-1-DKP-8, depending on their nitrogen substitution. In particular, DKP-1, DKP-2 and DKP-3 (bearing a benzyl group at nitrogen N-4, Figure 2) were prepared by making use of the serine ligation strategy exemplified in Scheme $1,{ }^{[17]}$ starting from either $(R)$ - or $(S)$ - $N$-(tert-butoxycarbonyl)aspartic acid $\beta$-allyl ester $\mathbf{1 1}^{[18]}$ or $(R)$ - or $(S)-N$ benzylserine methyl ester 12. ${ }^{[19]}$ Direct coupling of these fragments (HATU, $i \mathrm{Pr}_{2} \mathrm{NEt}$ or EDC, DMAP) led to the iso-

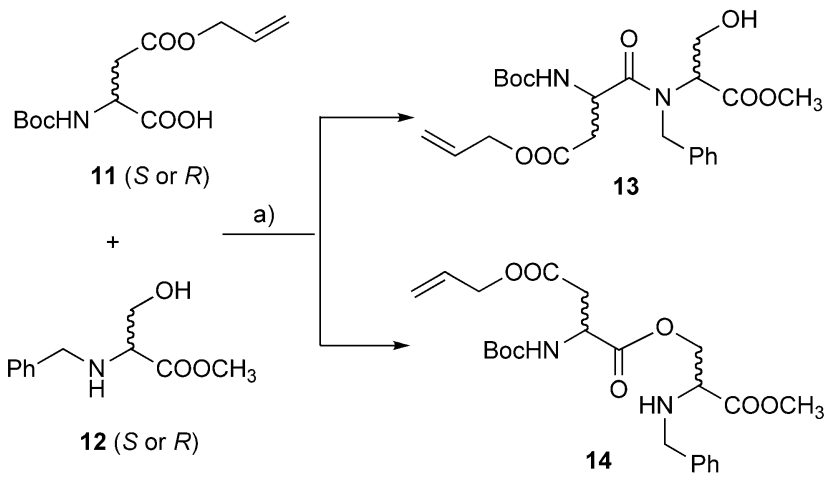

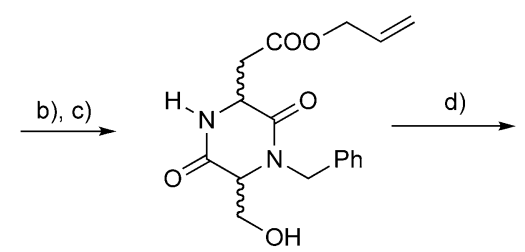

15

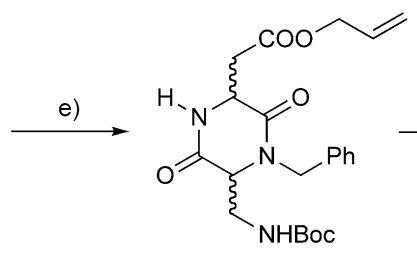

17

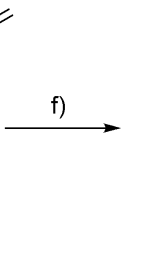<smiles>C=CCOC(=O)C[C@H]1NC(=O)[C@H](CN)N(Cc2ccccc2)C1=O</smiles>

16

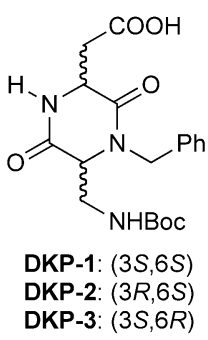

Scheme 1. Synthesis of DKP-1, DKP-2 and DKP-3 by the serine ligation strategy. a) EDC.HCl, DMAP, $\mathrm{CH}_{2} \mathrm{Cl}_{2}, 94 \%$; b) TFA/ $\mathrm{CH}_{2} \mathrm{Cl}_{2} \quad 1: 2$; c) DIPEA, $i \mathrm{PrOH}, 90 \%$ over two steps; d) $\mathrm{HN}_{3}$, DIAD, $\mathrm{PPh}_{3}, \mathrm{CH}_{2} \mathrm{Cl}_{2} /$ toluene, $51 \% S, S ; 80 \% S, R$ or $R, S$; e) $\mathrm{Me}_{3} \mathrm{P}$, BocON, THF, $76 \%$ f) pyrrolidine, $\mathrm{PPh}_{3},\left[\mathrm{Pd}\left(\mathrm{PPh}_{3}\right)_{4}\right], \mathrm{CH}_{2} \mathrm{Cl}_{2}, 99 \%$. peptides $\mathbf{1 4}$ in high yield, rather than forming the expected dipeptides 13. As a matter of fact, selective $O$-acylation of the unprotected $\beta$-hydroxyl group of $N$-benzylserine methyl ester is preferred to the formation of the tertiary amide and the resulting ester bond is stable in solution to $O, N$-acyl transfer. ${ }^{[17]}$ The $O, N$-acyl migration was then triggered by cleavage of the Boc protecting group and treatment with a base, which also promoted the simultaneous cyclization to the diketopiperazine 15. The introduction of the nitrogen functionality was then realized through a Mitsunobu-type reaction by using $\mathrm{HN}_{3}$. Tol in a toluene/dichloromethane solution, to obtain azide $\mathbf{1 6}$ in a moderate $(51 \%$; cis: $S, S)$ to good yield ( $80 \%$; trans: $S, R$ or $R, S) .{ }^{[20]}$ Finally, a one-pot Staudinger reduction/Boc protection ${ }^{[21]}$ yielded the DKP scaffold allyl ester 17, which was de-allylated ${ }^{[22]}$ to give the amino acid derivatives DKP-1, DKP-2 and DKP-3 in a quantitative yield.

Scaffold DKP-8, bearing a carboxyethyl side chain, was obtained through a similar synthesis strategy starting from $(S)$ - $N$-benzylserine methyl ester 12 and $(R)-N$-(tert-butoxycarbonyl)glutamic acid $\gamma$-methyl ester $\mathbf{1 8}$ (Scheme 2). ${ }^{[23]}$ Also in this case, direct coupling of the fragments afforded the isopeptide 19, which was deprotected and cyclized to the diketopiperazine 20. Azidation of the $-\mathrm{CH}_{2} \mathrm{OH}$ group through a Mitsunobu reaction, reduction by catalytic hydrogenation, protection with $\mathrm{Boc}_{2} \mathrm{O}$ and final hydrolysis of the methylester afforded DKP-8.

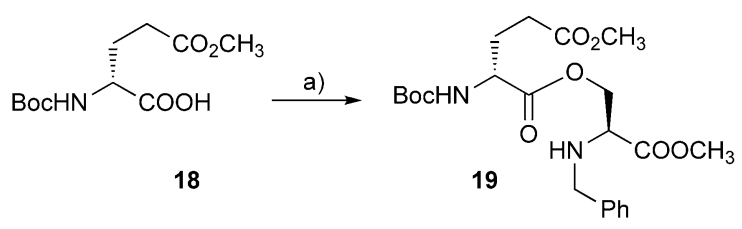

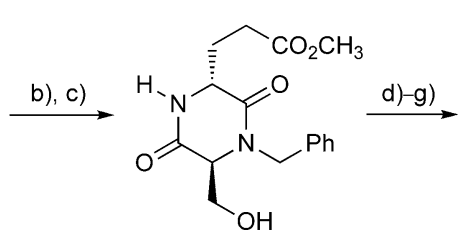

20

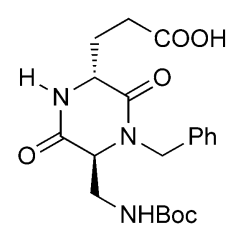

DKP-8
Scheme 2. Synthesis of DKP-8: a) 12, EDC. HCl, DMAP, $\mathrm{CH}_{2} \mathrm{Cl}_{2}, 59 \%$; b) TFA $/ \mathrm{CH}_{2} \mathrm{Cl}_{2} 1: 2$; c) DIPEA, $i \mathrm{PrOH}, 93 \%$ over two steps; d) $\mathrm{HN}_{3}$, DIAD, $\mathrm{PPh}_{3}, \mathrm{CH}_{2} \mathrm{Cl}_{2}$ /toluene/DMF; e) $\mathrm{H}_{2}, \mathrm{Pd} / \mathrm{C}, \mathrm{THF}$; f) $\mathrm{Boc}_{2} \mathrm{O}, \mathrm{THF}$; g) $\mathrm{LiOH}, \mathrm{THF} / \mathrm{H}_{2} \mathrm{O}_{2} 1: 1,43 \%$ over four steps.

For the preparation of diketopiperazines DKP-4 and DKP-6 (bearing a benzyl group at nitrogen N-1, Figure 2), the coupling of Boc-serine to $N$-benzyl-aspartic acid dimethylester 21 ${ }^{[24]}$ was envisaged (Scheme 3 ). The serine hydroxyl group required protection to avoid self-condensation, and the commercially available Boc-serine tert-butyl ether was initially treated with $N$-Bn-Asp dimethyl ester $\mathbf{2 1}$ by using several coupling agents: with HATU, ${ }^{[25]} \mathrm{PyBrOP}^{[26]}$ and DPPA $^{[27]}$ no product was detected; use of the acyl fluoride, [obtained by treatment of $\operatorname{Boc}-\operatorname{Ser}(\mathrm{O} t \mathrm{Bu})$ with cyanuric 
<smiles>CCCCOC[C@H](NC(=O)OCCCC)C(=O)OC(=O)[C@H](COCCC)NCc1ccccc1</smiles><smiles>COC(=O)C[C@H](C(=O)OC)N(Cc1ccccc1)C(=O)[C@H](COC(C)(C)C)NC(=O)OCc1ccccc1</smiles>

Scheme 3. Synthesis of dipeptide 22: a) $\mathrm{CH}_{2} \mathrm{Cl}_{2}, 80 \%$.

fluoride] afforded the coupling product in a modest $15 \%$ yield, whereas use of the mixed anhydride [obtained by treatment of $\mathrm{Boc}-\mathrm{Ser}(\mathrm{O} t \mathrm{Bu})$ with $i \mathrm{BuOCOCl}]$ gave the corresponding iso-butyl carbamate. Finally, preformation of the symmetric Boc-Ser $(\mathrm{O} t \mathrm{Bu})$ anhydride $(\mathrm{DCC})^{[28]}$ and coupling to $\mathrm{N}$-Bn-Asp dimethyl ester $\mathbf{2 1}$ afforded the corresponding dipeptide $\mathbf{2 2}$ in a satisfactory $80 \%$ yield (Scheme 3 ).

In order to simplify the synthesis sequence and avoid the use of an additional protecting group $(t \mathrm{Bu})$, the hydroxyl group of Boc-Ser-OMe (either L or D ${ }^{[20 \mathrm{a}]}$ was directly transformed into the corresponding azide under Mitsunobu conditions in $78 \%$ yield (Scheme 4 ).<smiles>COC(=O)NC[C@@H](C)C(=O)N[C@@H](CO)C(=O)OC</smiles><smiles>CC(C)(C)OC(=O)N[C@@H](CN)C(=O)OC(=O)[C@H](CN)NC(=O)OC(C)(C)C</smiles>

Scheme 4. Synthesis of symmetric anhydride 24: a) $\mathrm{HN}_{3}$, DIAD, $\mathrm{PPh}_{3}$, THF, $78 \%$; b) LiOH, THF $/ \mathrm{H}_{2} \mathrm{O}$ 1:1, quantitative; c) DCC, $\mathrm{CH}_{2} \mathrm{Cl}_{2}$, quantitative.

The resulting product was then saponified with $\mathrm{LiOH}$ and the freshly prepared acid $\mathbf{2 3}$ was treated with DCC to give the symmetric anhydride $\mathbf{2 4}$ in a quantitative yield, which was isolated by filtering off DCU and solvent evaporation, and was immediately used in the next synthesis step without further purification. Coupling of 3-azido-2- $N$-tert-butoxycarbonylaminopropionic anhydride (24) to $N$-benzyl-aspartic acid dimethylester (21) occurred in $80 \%$ yield, whereas the subsequent Boc cleavage and cyclization to diketopiperazine 26 were nearly quantitative (Scheme 5).

At this stage, diketopiperazine 26 was split in two portions. One portion was subjected to catalytic hydrogenation of the azide, Boc protection and final hydrolysis of the methyl ester to afford diketopiperazines DKP-4 and DKP-6 in $90 \%$ overall yield (Scheme 6).

A second portion of diketopiperazine $\mathbf{2 6}$ was alkylated at nitrogen N-4 (benzyl bromide, KHMDS) to afford the corresponding bis-benzylated derivative. One-pot Staudinger re-

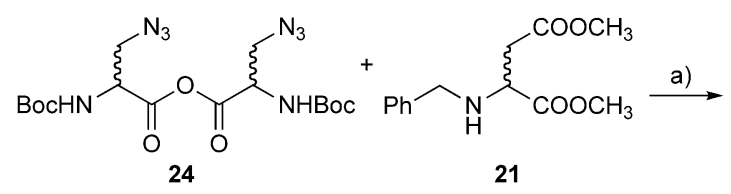<smiles>COC(=O)C(CCOC(C)=O)N(Cc1ccccc1)C(=O)[C@H](CN)NC(=O)c1ccccc1</smiles>

25<smiles>COC(=O)C[C@H]1C(=O)N[C@@H](CN)C(=O)N1Cc1ccccc1</smiles>

Scheme 5. Synthesis of diketopiperazine 26: a) $\mathrm{CH}_{2} \mathrm{Cl}_{2}, 80 \%$; b) TFA/ $\mathrm{CH}_{2} \mathrm{Cl}_{2} 1: 2 ;$ c) DIPEA, $i \mathrm{PrOH}, 90 \%$ over two steps.<smiles>COC(=O)C[C@H]1C(=O)N[C@H](CN)C(=O)N1Cc1ccccc1</smiles>

26<smiles>CC(C)(C)OC(=O)NC[C@H]1NC(=O)[C@H](CC(=O)O)N(Cc2ccccc2)C1=O</smiles>

DKP-4: $(3 R, 6 S)$

DKP-6: $(3 S, 6 R)$
Scheme 6. Synthesis of DKP-4 and DKP-6: a) $\mathrm{H}_{2}$, Pd/C, THF; b) $\mathrm{Boc}_{2} \mathrm{O}$, THF; c) $\mathrm{LiOH}, \mathrm{THF} / \mathrm{H}_{2} \mathrm{O}$ 1:1, $90 \%$ over three steps.

duction/Boc protection ${ }^{[21]}$ followed by saponification of the methyl ester afforded DKP-5 and DKP-7 in $75 \%$ overall yield (Scheme 7).

Diketopiperazines DKP-1-DKP-8 were then incorporated into the cyclic RGD derivatives $\mathbf{9 ,} \mathbf{1 0}$ and 27-32 (Figure 4). A solution phase synthesis strategy was adopted, by using Boc-Arg(Mtr), Gly-OBn and Cbz-Asp(OtBu)-OH. The dipeptide Boc-Arg(Mtr)-Gly-OBn was Boc-deprotected and coupled to the acid of the appropriate diketopiperazine scaffold. Subsequent Boc deprotection of the DKP amino group and coupling of the aspartic derivative $\mathrm{Cbz}-\mathrm{Asp}(\mathrm{O} t \mathrm{Bu})-\mathrm{OH}$ afforded the linear peptidomimetic Cbz-Asp(OtBu)-DKP$\operatorname{Arg}(\mathrm{Mtr})-\mathrm{Gly}-\mathrm{OBn}$, which was deprotected by hydrogenolysis ( $\mathrm{Cbz}$ and $\mathrm{Bn})$ and was subjected to macrolactamization (for detailed conditions, see the Supporting Information).<smiles>COC(=O)C[C@H]1C(=O)N[C@H](CN)C(=O)N1Cc1ccccc1</smiles>

26<smiles>O=C(O)C[C@H]1C(=O)N(Cc2ccccc2)[C@H](CNC(=O)OCc2ccccc2)C(=O)N1Cc1ccccc1</smiles>

DKP-5: $(3 R, 6 S)$

DKP-7: $(3 S, 6 R)$
Scheme 7. Synthesis of DKP-5 and DKP-7: a) KHMDS, BnBr, THF/ DMF 7:3; b) $\mathrm{Me}_{3} \mathrm{P}$, BocON, THF; c) $\mathrm{LiOH}, \mathrm{THF} / \mathrm{H}_{2} \mathrm{O} 1: 1,75 \%$ over four steps. 
<smiles>[Y20]C(=O)N[C@@H](CCCNC(=N)N)C(=O)NCC(=O)N[C@@H](CC(=O)O)C(=O)NC[C@H]1C(=O)N([R])C(=O)N1[R1]</smiles>

$9=$ cyclo- $($ DKP-1-RGD $)=3 S, 6 S, \mathrm{R}^{1}=\mathrm{H}, \mathrm{R}^{2}=\mathrm{CH}_{2} \mathrm{Ph}, n=1$

$10=$ cyclo- $\left(\right.$ DKP-2-RGD) $=3 R, 6 \mathrm{~S}, \mathrm{R}^{1}=\mathrm{H}, \mathrm{R}^{2}=\mathrm{CH}_{2} \mathrm{Ph}, n=1$

$27=$ cyclo- $\left(\right.$ DKP-3-RGD) $=3 S, 6 R, \mathrm{R}^{1}=\mathrm{H}, \mathrm{R}^{2}=\mathrm{CH}_{2} \mathrm{Ph}, n=1$

$28=$ cyclo- $($ DKP-4-RGD $)=3 R, 6 \mathrm{~S}, \mathrm{R}^{1}=\mathrm{CH}_{2} \mathrm{Ph}, \mathrm{R}^{2}=\mathrm{H}, n=1$

$29=$ cyclo- $($ DKP-5-RGD $)=3 R, 6 \mathrm{~S}, \mathrm{R}^{1}=\mathrm{CH}_{2} \mathrm{Ph}, \mathrm{R}^{2}=\mathrm{CH}_{2} \mathrm{Ph}, n=1$

$30=$ cyclo- $\left(\right.$ DKP-6-RGD) $=3 S, 6 R, \mathrm{R}^{1}=\mathrm{CH}_{2} \mathrm{Ph}, \mathrm{R}^{2}=\mathrm{H}, n=1$

$31=$ cyclo- $\left(\right.$ DKP-7-RGD) $=3 \mathrm{~S}, 6 \mathrm{R}, \mathrm{R}^{1}=\mathrm{CH}_{2} \mathrm{Ph}, \mathrm{R}^{2}=\mathrm{CH}_{2} \mathrm{Ph}, n=1$

$32=$ cyclo- $($ DKP-8-RGD $)=3 S, 6 R, \mathrm{R}^{1}=\mathrm{H}, \mathrm{R}^{2}=\mathrm{CH}_{2} \mathrm{Ph}, n=2$

Figure 4. Cyclic RGD peptidomimetics containing bifunctional DKP scaffolds.

Several methodologies were screened for the ring closure, and the best yields were obtained for all the products (except 27) by using HATU/HOAT as coupling agents in a 1:4:4:6 substrate/HATU/ $\mathrm{HOAT} / i \mathrm{Pr}_{2} \mathrm{NEt}$ molar ratio and a substrate concentration of $1.4 \mathrm{~mm}$ in DMF ${ }^{[11 \mathrm{~b}]}$ In the case of cyclo[DKP-3-RGD] (27) the highest yield $(75 \%)$ was obtained by using a 1:3:6 substrate/DPPA $/ i \operatorname{Pr}_{2} \mathrm{NEt}$ molar ratio with the same substrate concentration (1.4 mM) in DMF. ${ }^{[29]}$ A final side-chain deprotection (TFA/thioanisole/ethanedithiol/anisole 90:5:3:2) and preparative HPLC purification afforded the desired compounds $\mathbf{9 ,} \mathbf{1 0}$ and 27-32 for the biological screening.

In the case of the $N$-dibenzyl derivatives 29 and 31, the molecules can exist as two different separable conformers (diastereomers) due to hindered rotation of one ring around the other, in a way reminiscent of the ansa-cyclopeptides ${ }^{[30]}$ (i.e., the DKP $N$-benzyl group cannot pass inside the macrolactam ring).

With 29, we were able to isolate only one diastereomer, either because it was formed exclusively or because it was formed predominantly and the minor one was not detected/ isolated. With 31, two diastereomers were isolated in a 2(A):1(B) ratio (Figure 5). The two diastereomers were formed in the macrolactamization step, as shown by the two sets of peaks (2:1 ratio) in the ${ }^{1} \mathrm{H}$ NMR spectrum (see the Supporting Information), but co-eluted in the HPLC. However, after side-chain deprotection, the two diastereomers could be separated, analyzed and subjected to the binding assays (vide infra).

Integrin receptor competitive binding assays: The cyclic RGD peptidomimetics were examined in vitro for their ability to inhibit biotinylated vitronectin binding to the purified $\alpha_{\mathrm{v}} \beta_{3}$ and $\alpha_{\mathrm{v}} \beta_{5}$ receptors (Table 1 ).
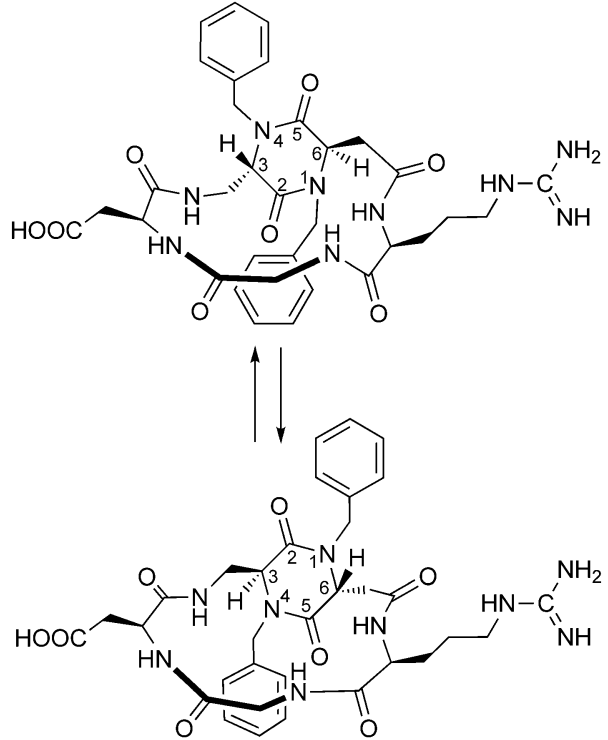

Figure 5. Compounds $\mathbf{3 1} \mathbf{A}$ and $\mathbf{3 1} \mathbf{B}$, diastereomers of $\mathbf{3 1}$ due to hindered rotation.

Table 1. Inhibition of biotinylated vitronectin binding to $\alpha_{\mathrm{v}} \beta_{3}$ and $\alpha_{\mathrm{v}} \beta_{5}$ receptors.

\begin{tabular}{llcc} 
Ligand & Structure & $\begin{array}{c}\alpha_{\mathrm{v}} \beta_{3} \mathrm{IC}_{50} \\
{[\mathrm{~nm}]^{[\mathrm{a}]}}\end{array}$ & $\begin{array}{c}\alpha_{\mathrm{v}} \beta_{5} \mathrm{IC}_{50} \\
{[\mathrm{~nm}]^{[\mathrm{a}]}}\end{array}$ \\
\hline $\mathbf{9}$ & cyclo-[DKP-1-RGD] & $3898 \pm 418$ & $>10^{4}$ \\
$\mathbf{9}$ & cyclo-[DKP-2-RGD] & $3.2 \pm 2.7$ & $114 \pm 99$ \\
$\mathbf{9}$ & cyclo-[DKP-3-RGD] & $4.5 \pm 1.1$ & $149 \pm 25$ \\
$\mathbf{3 0}$ & cyclo-[DKP-4-RGD] & $7.6 \pm 4.3$ & $216 \pm 5$ \\
$\mathbf{3 1}$ & cyclo-[DKP-5-RGD] & $12.2 \pm 5.0$ & $131 \pm 29$ \\
$\mathbf{3 1 ~ B ~}$ & cyclo-[DKP-6-RGD] & $2.1 \pm 0.6$ & $79 \pm 3$ \\
yclo-[RGDfV] & cyclo-[DKP-7-RGD]-A & $220.2 \pm 82.3$ & $>10^{4}$ \\
cyclo-[DKP-7-RGD]-B & $0.2 \pm 0.09$ & $109 \pm 15$ \\
\hline & cyclo-[DKP-8-RGD] & $17.7 \pm 0.1$ & $420 \pm 37$ \\
& cyclo-[RGDfV] & $3.2 \pm 1.3$ & $7.5 \pm 4.8$ \\
\hline
\end{tabular}

$\mathrm{IC}_{50}$ values were calculated as the concentration of compound required for $50 \%$ inhibition of biotinylated vitronectin binding as estimated by GraphPad Prism software; ll values are the arithmetic mean \pm SD of triplicate determinations.

Screening assays were performed by incubating the immobilized integrin receptors with various concentrations $\left(10^{-12}\right.$ $10^{-5} \mathrm{M}$ ) of the RGD ligands $\mathbf{9}, \mathbf{1 0}, \mathbf{2 7}-\mathbf{3 2}$ in the presence of biotinylated vitronectin $\left(1 \mu \mathrm{g} \mathrm{mL}^{-1}\right)$, and measuring the concentration of bound vitronectin in the presence of the competitive ligands. The ability of the new compounds to inhibit the binding of vitronectin to the isolated $\alpha_{v} \beta_{3}$ and $\alpha_{v} \beta_{5}$ receptors was compared with that of the reference compounds c(RGDfV) $)^{[31]}$ and ST1646 ${ }^{[11]}$ (Figure 1). The results are collected in Table 1. Low nanomolar values were obtained with all the ligands except cyclo-[DKP-1-RGD] (9), which incorporates a cis DKP, and ligand $\mathbf{3 1} \mathbf{A}$. The behavior of this last ligand is peculiar, considering that the diastereomeric compound $31 \mathrm{~B}$ (see above for the definition of the two diastereomers) is the most potent ligand of this series, and it effectively inhibits the binding of vitronectin to the isolated $\alpha_{v} \beta_{3}$ receptor in subnanomolar concentration. Interestingly, unlike reference compounds $\mathrm{c}(\mathrm{RGDfV})$ and ST1646, the 
RGD peptidomimetics $\mathbf{1 0}$ and 27-32 were about 10-500-fold more selective for the $\alpha_{\mathrm{v}} \beta_{3}$ integrin with respect to the $\alpha_{\mathrm{v}} \beta_{5}$ in this kind of assay.

NMR spectroscopy characterization and conformational studies: The structure and connectivity of ligands $\mathbf{9 ,} \mathbf{1 0}$ and 27-32 and of their fully protected precursors were unambiguously assigned by means of mono- and bidimensional ${ }^{1} \mathrm{H}-$ and ${ }^{13} \mathrm{C}$ NMR spectroscopy.

The preferred conformations of the cyclic RGD peptidomimetics 9, 10 and 27-32 in aqueous solution were then investigated, with the aim of rationalizing the affinity of these compounds for the $\alpha_{\mathrm{v}} \beta_{3}$ receptor at a molecular level. Monodimensional ${ }^{1} \mathrm{H}$ NMR spectroscopy experiments were conducted to detect intramolecular hydrogen bonds, by measuring the chemical shift of the $\mathrm{N}-\mathrm{H}$ protons and their temperature coefficients $(\Delta \delta / \Delta T)$. NOESY spectra were recorded to investigate both sequential and long-range NOEs that provide evidence for preferred conformations. The relevant NMR spectroscopy data are summarized in Table 2.

As already mentioned in our preliminary studies, ${ }^{[16]}$ low affinity ligand 9 exists as an equilibrium of two different preferred conformations. The NOESY spectrum shows two mutually exclusive long-range NOE contacts. The crosspeak between DKP-NH 10 and $\mathrm{NH}_{\text {Asp }}$ (strong) is indicative of a $\beta$-turn conformation at Gly-Asp stabilized by a hydrogen bond between $\mathrm{DKP}-\mathrm{NH}_{10}$ and $\mathrm{Arg}-\mathrm{C}=\mathrm{O}$ (referred to as type I H-bonding pattern, Figure $6 \mathrm{~A})$. The chemical shift value $(\delta=7.46 \mathrm{ppm})$ and the $\Delta \delta / \Delta T$ value $\left(-2 \mathrm{ppbK}^{-1}\right)$ of the amide proton $\mathrm{DKP}-\mathrm{NH}_{10}$ indicate that this proton is strongly locked in an intramolecularly $\mathrm{H}$-bonded state. The cross-peak between $\mathrm{NH}_{\text {Gly }}$ and $\mathrm{NH}_{\text {Asp }}$ (medium) is indicative of an alternative $\beta$-turn conformation at Arg-Gly, stabilized by a hydrogen bond between Asp-NH and $\mathrm{C}(8)=\mathrm{O}$ (referred to as type II H-bonding pattern, Figure 6B).

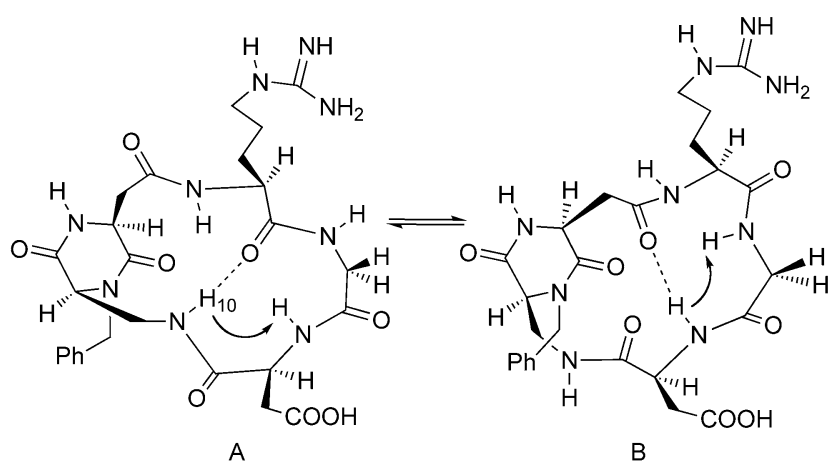

Figure 6. Preferred intramolecular hydrogen-bonded patterns proposed for compound 9 on the basis of spectroscopic data. The arrows indicate significant NOE contacts. A) Type I H-bonding pattern, Gly-Asp $\beta$-turn motif. B) Type II H-bonding pattern, Arg-Gly $\beta$-turn motif.

High affinity ligands $\mathbf{1 0}$ and $\mathbf{2 7}$ are apparently characterized by conformational mobility, as suggested by the values of chemical shifts and $\Delta \delta / \Delta T$ reported in Table 2 . The only exception is proton NH-Asp of $27(\delta=7.85 \mathrm{ppm}, \Delta \delta / \Delta T=$ $-3.5 \mathrm{ppb} \mathrm{K}^{-1}$ ), which might be involved in a type II H-bonding pattern (for definition of type II H-bonding pattern see Figure $6 \mathrm{~B}$ ). On the other hand, the presence in both cases of a $\mathrm{NOE}$ contact between $\mathrm{NH}_{\mathrm{Gly}}$ and $\mathrm{NH}_{\mathrm{Arg}}$ suggests the formation of a $\beta$-turn motif at DKP-Arg, stabilized by a hydrogen bond between $\mathrm{NH}_{\mathrm{Gly}}$ and $\mathrm{C}(5)=\mathrm{O}$ (referred to as type III H-bonding pattern, Figure 7). The presence of this $\mathrm{H}$ bond is also supported by the rather upfield chemical shift value of $\mathrm{NH}_{\text {Gly }}$ in these two ligands $(\delta=8.18$ and $8.00 \mathrm{ppm}$ for $\mathbf{1 0}$ and $\mathbf{2 7}$, respectively) and the relatively low temperature dependence $\left(-5.7\right.$ and $-4.5 \mathrm{ppbK}^{-1}$, respectively). The similarity of the NMR spectroscopy data and, hence, of the conformation of these two ligands is quite surprising, considering the opposite configuration of the diketo-

Table 2. ${ }^{1} \mathrm{H}$ NMR spectroscopy and NOE data of cyclic RGD peptidomimetics in water.

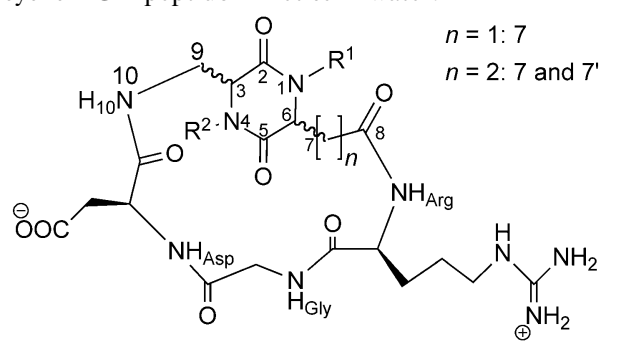

\begin{tabular}{|c|c|c|c|c|c|c|c|c|c|c|c|c|c|c|}
\hline \multirow{2}{*}{$\begin{array}{l}\text { Lig- } \\
\text { and }\end{array}$} & \multirow[t]{2}{*}{ Structure } & \multicolumn{6}{|c|}{$\delta[\mathrm{ppm}]$} & \multicolumn{6}{|c|}{$\Delta \delta / \Delta T\left[\mathrm{ppb} \mathrm{K}^{-1}\right]$} & \multirow{2}{*}{$\begin{array}{l}\text { Significant } \\
\text { NOE contacts }\end{array}$} \\
\hline & & $\mathrm{NH}_{1}$ & $\mathrm{NH}_{4}$ & $\mathrm{NH}_{10}$ & $\mathrm{NH}_{\mathrm{Arg}}$ & $\mathrm{NH}_{\mathrm{Gly}}$ & $\mathrm{NH}_{\text {Asp }}$ & $\mathrm{NH}_{1}$ & $\mathrm{NH}_{4}$ & $\mathrm{NH}_{10}$ & $\mathrm{NH}_{\mathrm{Arg}}$ & $\mathrm{NH}_{\mathrm{Gly}}$ & $\mathrm{NH}_{\text {Asp }}$ & \\
\hline 9 & cyclo-[DKP-1-RGD] & 8.35 & - & 7.46 & 8.40 & 8.75 & 8.10 & -7.3 & - & -2.0 & -7.0 & -8.0 & -3.7 & $\mathrm{NH}_{\mathrm{Asp}}-\mathrm{NH}_{10} ; \mathrm{NH}_{\mathrm{Asp}}-\mathrm{NH}_{\mathrm{Gly}}$ \\
\hline 10 & cyclo-[DKP-2-RGD] & 8.35 & - & 8.78 & 8.57 & 8.18 & 8.29 & -8.7 & - & -10.7 & -7.0 & -5.7 & -7.7 & $\mathrm{NH}_{\mathrm{Arg}}-\mathrm{NH}_{\mathrm{Gly}}$ \\
\hline 27 & cyclo-[DKP-3-RGD] & 8.10 & - & 8.28 & 8.80 & 8.00 & 7.85 & -5.7 & - & -8.5 & -6.0 & -4.5 & -3.5 & $\mathrm{NH}_{\mathrm{Arg}}-\mathrm{NH}_{\mathrm{Gly}}$ \\
\hline 28 & cyclo-[DKP-4-RGD] & - & 8.17 & 7.59 & 8.29 & 8.27 & 8.88 & - & -9.1 & -0.7 & -9.3 & -8.2 & -9.3 & - \\
\hline 29 & cyclo-[DKP-5-RGD] & - & - & 8.58 & 8.48 & 8.23 & 8.42 & - & - & -11.0 & -7.5 & -4.7 & -8.2 & $\mathrm{NH}_{\mathrm{Arg}}-\mathrm{NH}_{\mathrm{Gly}}$ \\
\hline 30 & cyclo-[DKP-6-RGD] & - & 8.07 & 7.90 & 8.32 & 8.35 & 8.80 & - & -4.9 & -5.1 & -7.6 & -6.7 & -8.0 & $\mathrm{NH}_{\mathrm{Asp}}-\mathrm{NH}_{10} ; \mathrm{NH}_{4}-\mathrm{NH}_{10}$ \\
\hline 31B & cyclo-[DKP-7-RGD]-B & - & - & 7.72 & 8.34 & 8.45 & 8.55 & - & - & -4.0 & -7.0 & -7.0 & -5.0 & $\mathrm{NH}_{\mathrm{Asp}}-\mathrm{NH}_{10}$ \\
\hline 32 & cyclo-[DKP-8-RGD] & 7.75 & - & 8.16 & 8.42 & 8.27 & 8.14 & -5.3 & - & -8.5 & -7.2 & -6.2 & -5.0 & $\mathrm{NH}_{1}-\mathrm{NH}_{\mathrm{Arg}}$ \\
\hline
\end{tabular}



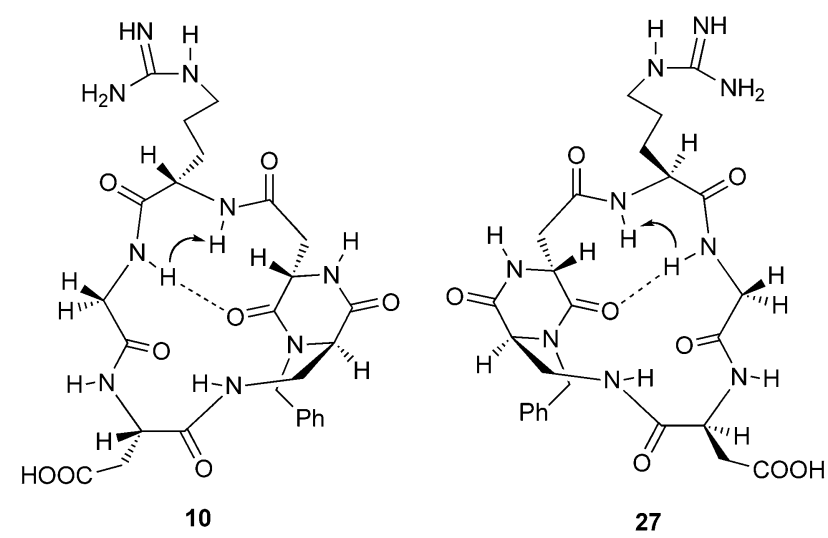

27

Figure 7. Preferred intramolecular hydrogen-bonded pattern proposed for compound $\mathbf{1 0}$ and $\mathbf{2 7}$ on the basis of spectroscopic data. The arrows indicate significant NOE contacts. The DKP-Arg $\beta$-turn motif is referred to as type III H-bonding pattern.

piperazine scaffold [DKP-2 $(3 R, 6 S)$ in $\mathbf{1 0} ; \mathbf{D K P}-\mathbf{3}(3 S, 6 R)$ in 27], which should impart a different stereochemical orientation to the two side arms of the diketopiperazine. This conformational similarity can be interpreted in terms of a quasienantiomeric structure of the two ligands (excluding the configuration of the remote RD amino acid side chains, Figure 7).

High affinity ligands $\mathbf{2 8}$ and $\mathbf{3 0}$, featuring the diketopiperazine scaffolds DKP-4 $(3 R, 6 S)$ and DKP-6 $(3 S, 6 R)$, respectively (with the benzyl substitution at the endocyclic nitrogen $\mathrm{N}-1$, instead of N-4), show a different NMR pattern.

In particular, ligand $\mathbf{3 0}$ is characterized by a rather strong NOE contact between $\mathrm{NH}_{\text {Asp }}$ and $\mathrm{NH}_{10}$ and a moderate one involving $\mathrm{NH}_{4}$ and $\mathrm{NH}_{10}$. These two contacts are mutually exclusive and are hence indicative of an equilibrium between two different conformations, respectively, type I and type IV binding modes (Figure $8 \mathrm{~A}$ and $\mathrm{B}$ ). The hydrogen bonded status of the two amide protons $\mathrm{NH}_{4}$ and $\mathrm{NH}_{10}$, as indicated by their rather low temperature dependence $(-4.9$ and $-5.1 \mathrm{ppb} \mathrm{K}^{-1}$, respectively) and quite upfield chemical shift values ( $\delta=8.07$ and $7.90 \mathrm{ppm}$, respectively) corroborate

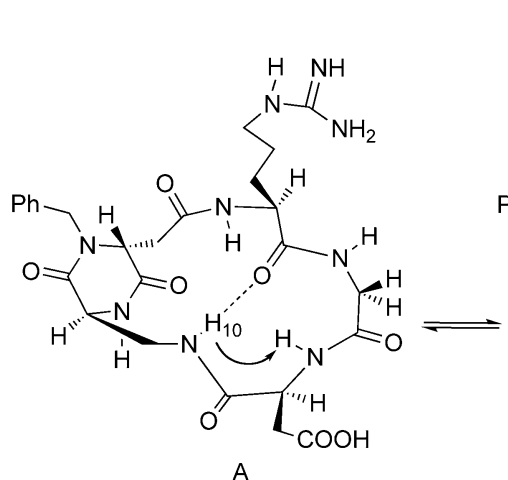

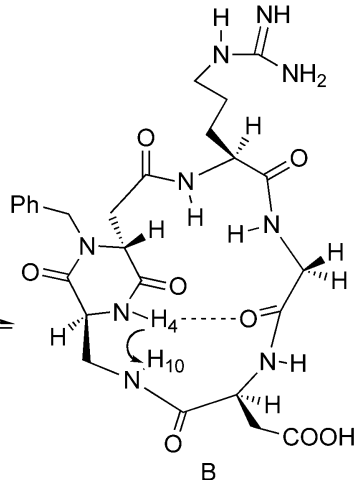

B
Figure 8. Preferred intramolecular hydrogen-bonded pattern proposed for compound $\mathbf{3 0}$ on the basis of spectroscopic data. A) Type I H-bonding pattern, Gly-Asp $\beta$-turn motif. B) Type IV H-bonding pattern, pseudo- $\beta$ turn at Asp-DKP. The arrows indicate significant NOE contacts. this assumption. The type IV H-bonding pattern could feature a pseudo- $\beta$-turn at Asp-DKP stabilized by a hydrogen bond between $\mathrm{NH}_{4}$ and Gly- $\mathrm{C}=\mathrm{O}$ (NOE contact between $\mathrm{NH}_{4}$ and $\mathrm{NH}_{10}$ ).

Ligand 28, on the other hand, is characterized by the absence of relevant NOE contacts, a very low temperature dependence $\left(-0.7 \mathrm{ppb} \mathrm{K}^{-1}\right)$ and a quite upfield chemical shift value $(\delta=7.59 \mathrm{ppm})$ for proton $\mathrm{NH}_{10}$. These two features suggest a type I H-bonding pattern (for definition of type I $\mathrm{H}$-bonding pattern, Figure $6 \mathrm{~A}$ or $8 \mathrm{~A}$ ), notwithstanding the apparent lack of NOE contact between $\mathrm{NH}_{\text {Asp }}$ and $\mathrm{NH}_{10}$.

The dibenzylated diketopiperazine containing peptidomimetics 29 and 31 were eventually studied. Ligand 29 shows NMR spectroscopy features similar to ligand $\mathbf{1 0}$ (for definition of type III H-bonding pattern, see Figure 7): a NOE contact between $\mathrm{NH}_{\text {Gly }}$ and $\mathrm{NH}_{\text {Arg }}$ and a rather shielded $\mathrm{NH}_{\text {Gly }}(\delta=8.23 \mathrm{ppm})$ with a relatively low temperature coefficient $\left(-4.7 \mathrm{ppb} \mathrm{K}^{-1}\right)$. As discussed in the synthesis section, ligand cyclo-[DKP-7-RGD] was obtained as a mixture of two diastereomers $31 \mathbf{A}$ and $\mathbf{3 1 B}$, the conformations of which in solution were studied separately. In particular, the low affinity ligand $\mathbf{3 1} \mathbf{A}$ displayed two mutually exclusive NOE contacts between $\mathrm{NH}_{\mathrm{Arg}}$ and $\mathrm{NH}_{\mathrm{Gly}}$ and between $\mathrm{NH}_{\mathrm{Asp}}$ and $\mathrm{NH}_{\mathrm{Gly}}$. These three protons, on the other hand, show also a rather strong hydrogen bonded status, as indicated by their low temperature dependence and, at least for $\mathrm{NH}_{\text {Asp }}$ and $\mathrm{NH}_{\mathrm{Gly}}$, their upfield chemical shift (Table 2). These data indicate an equilibrium between two different conformations: one displaying a type III H-bonding pattern ( $\beta$-turn at DKP-Arg, Figure 7) and a second one showing a type II H-bonding pattern ( $\beta$-turn at Arg-Gly, Figure 6B), like the low-affinity ligand 9, that is, cyclo-[DKP-1-RGD]. Finally, high affinity ligand $\mathbf{3 1} \mathbf{B}$ shows a single NOE contact between $\mathrm{NH}_{\text {Asp }}$ and $\mathrm{NH}_{10}$ and a hydrogen bonded status for $\mathrm{NH}_{10}\left(\delta=7.72 \mathrm{ppm}\right.$ and $\Delta \delta / \Delta T=-4 \mathrm{ppbK}^{-1}, \quad$ Table 2$)$. These values are indicative of a type I H-bonding pattern (Figure $6 \mathrm{~A}$ or $8 \mathrm{~A}$ ).

Compound 32, containing the carboxyethyl diketopiperazine scaffold DKP-8, is characterized by temperature coefficients of amide protons (Table 2) greater than $5 \mathrm{ppbK}^{-1}$; this suggests an equilibrium between different conformations. The NOESY spectrum of this ligand shows a strong long-range NOE contact that involves $\mathrm{DKP}-\mathrm{NH}_{1}$ and $\mathrm{NH}_{\mathrm{Arg}}$ (Figure 9). This contact is indicative of a conformation stabilized by a hydrogen bond between $\mathrm{NH}_{1}$ and $\mathrm{Arg}-\mathrm{C}=\mathrm{O}$ (referred to as type $\mathrm{V} \mathrm{H}$-bonding pattern). The involvement of $\mathrm{NH}_{1}$ in a hydrogen bond is also confirmed by its relatively low chemical shift value $(\delta=7.75 \mathrm{ppm})$.

\section{Computational studies}

Conformational analysis: Conformational studies of the cyclic RGD peptidomimetics were performed by mixedmode Metropolis Monte Carlo/Stochastic Dynamics (MC/ SD) simulations, ${ }^{[32]}$ by using the implicit water GB/SA solvation model ${ }^{[33]}$ and the OPLS_2001 force field. ${ }^{[34,35]}$ As outlined in the Introduction, a key parameter for the RGD fit- 


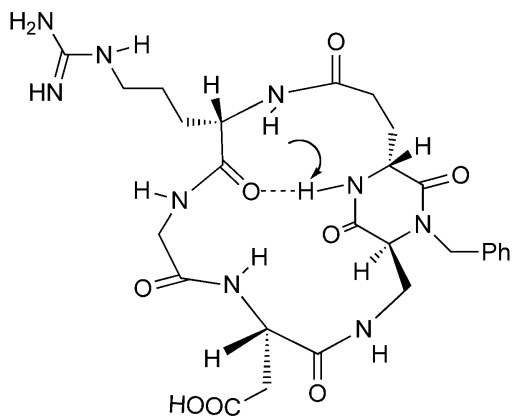

Figure 9. Preferred intramolecular hydrogen-bonded pattern (type V Hbonding pattern) proposed for compound $\mathbf{3 2}$ on the basis of spectroscopic data. The arrows indicate significant NOE contacts.

ting into the active site of the $\alpha_{\mathrm{V}} \beta_{3}$ integrin is the distance of about $9 \AA$ between the $C_{\beta}$ atoms of Asp and Arg, imparted by an extended conformation of the Arg-Gly-Asp sequence. ${ }^{[5]}$ In such an extended conformation, the carboxylate and guanidinium groups are properly positioned to effectively exert their function of electrostatic clamp (vide infra for the relevant docking studies).

As mentioned in our preliminary studies, ${ }^{[16]}$ three-dimensional structures satisfying long-range NOE contacts were generated for low affinity ligand 9 by performing two $10 \mathrm{~ns}$ restrained $\mathrm{MC} / \mathrm{SD}$ simulations and applying the DKP-NH $\mathrm{NH}_{\text {Asp }}$ or the $\mathrm{NH}_{\mathrm{Asp}} / \mathrm{NH}_{\mathrm{Gly}}$ distance restraint derived from the NOESY spectra described in the relevant section above. More than $90 \%$ of the conformations sampled during the first simulation adopted a non-extended arrangement of the RGD sequence characterized by a $\beta$-turn at Gly-Asp and the presence of the corresponding hydrogen bond between $\mathrm{DKP}-\mathrm{NH}_{10}$ and $\mathrm{Arg}-\mathrm{C}=\mathrm{O}$. In addition, the formation of a $\gamma$ turn at Gly stabilized by the hydrogen bond between $\mathrm{NH}_{\text {Asp }}$ and $\mathrm{Arg}-\mathrm{C}=\mathrm{O}$ was observed for $40 \%$ of the simulation. A $\mathrm{C} \beta(\mathrm{Arg})-\mathrm{C} \beta(\mathrm{Asp})$ average distance of $7.4 \AA$ was obtained during this $\mathrm{MC} / \mathrm{SD}$ calculation. A representative energy minimized conformation selected by cluster analysis and featuring both $\mathrm{H}$ bonds is shown in Figure $10 \mathrm{~A}$ (type I-cis H-bonding pattern).

Approximately $60 \%$ of the conformations sampled during the simulation of 9 featuring the $\mathrm{NH}_{\mathrm{Asp}} / \mathrm{NH}_{\mathrm{Gly}}$ distance restraint, adopted a non-extended arrangement of the RGD sequence characterized by a $\beta$-turn at Arg-Gly and the corresponding hydrogen bond between $\mathrm{NH}_{\text {Asp }}$ and $\mathrm{C}(8)=\mathrm{O}$. In addition, the formation of a $\gamma$-turn at Arg stabilized by the hydrogen bond between $\mathrm{NH}_{\text {Gly }}$ and $\mathrm{C}(8)=\mathrm{O}$ was observed for $40 \%$ of the simulation. The $C \beta(A r g)-C \beta(A s p)$ average distance in this MC/SD calculation was $6.8 \AA$. A representative energy minimized conformation selected by cluster analysis and featuring both $\mathrm{H}$ bonds is shown in Figure $10 \mathrm{~B}$ (type II H-bonding pattern).

The NOESY spectra of high affinity ligands $\mathbf{1 0}$ (containing $N$-4-benzylated DKP-2, 3R,6S), 27 (containing $N$-4-benzylated DKP-3, 3S,6R) and 29 (containing $N$-dibenzylated DKP-5 $3 R, 6 S$ ) showed only one relevant long-range contact between $\mathrm{NH}_{\mathrm{Gly}}$ and $\mathrm{NH}_{\mathrm{Arg}}$ : this $\mathrm{NOE}$ is indicative of a $\beta$ -
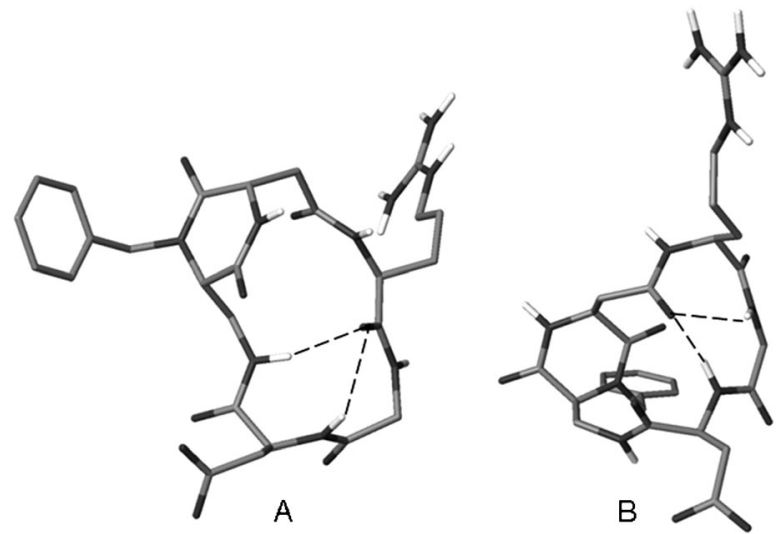

Figure 10. Structures of 9 as obtained by restrained MC/SD simulations based on experimental distance information, after energy minimization. A) Type I-cis H-bonding pattern, $\gamma$-turn at Gly and $\beta \mathrm{II}^{\prime}$-turn at Gly-Asp $[\mathrm{C} \beta(\mathrm{Arg})-\mathrm{C} \beta(\mathrm{Asp})=7.9 \AA]$. B) Type II H-bonding pattern, $\gamma$-turn at Arg and $\beta \mathrm{II}^{\prime}$-turn at Arg-Gly $[\mathrm{C} \beta(\mathrm{Arg})-\mathrm{C} \beta(\mathrm{Asp})=6.6 \AA]$. Tube representation: $\mathrm{O}, \mathrm{N}$ in dark gray, $\mathrm{C}$ in light gray and $\mathrm{N}-\mathrm{H}$ hydrogen atoms in white; for the sake of clarity, all $\mathrm{H}$ atoms bound to carbon are omitted.

turn motif at DKP-Arg stabilized by a hydrogen bond between $\mathrm{NH}_{\text {Gly }}$ and $\mathrm{C}(5)=\mathrm{O}$ (Figure 7, type III H-bonding pattern). The distance restraint corresponding to the NOE contact between $\mathrm{NH}_{\mathrm{Gly}}$ and $\mathrm{NH}_{\mathrm{Arg}}$ was applied in the $10 \mathrm{~ns} \mathrm{MC/}$ SD simulations of compounds 10, 27 and 29. More than $90 \%$ of the conformations sampled during each of these simulations adopted an extended arrangement of the RGD sequence characterized by a pseudo- $\beta$-turn at DKP-Arg and the formation of the corresponding hydrogen bond between the $\mathrm{NH}_{\mathrm{Gly}}$ and $\mathrm{C}(5)=\mathrm{O}$. Interestingly, only for compound 27, the additional formation of a $\beta$-turn at Arg-Gly stabilized by the hydrogen bond between $\mathrm{NH}_{\text {Asp }}$ and $\mathrm{C}(8)=\mathrm{O}$ was observed for $15 \%$ of the simulations. These results and the NMR spectroscopy data (showing $\delta=7.85 \mathrm{ppm}$ and $\Delta \delta /$ $\Delta T=-3.5 \mathrm{ppb} \mathrm{K}^{-1}$ for $\mathrm{NH}_{\mathrm{Asp}}$ of 27) suggest the contribution of a type II/type III H-bonding pattern to the conformational equilibrium of 27 (mainly populated by a type III Hbonding pattern). $C \beta(A r g)-C \beta(A s p)$ average distances of 9.3, 8.8, and $9.1 \AA$ were obtained during the MC/SD calculations of 10, 27 and 29, respectively. A representative energy minimized conformation selected by cluster analysis and featuring the $\mathrm{H}$ bond between the Gly-NH and $\mathrm{C}(5)=\mathrm{O}$ (type III H-bonding pattern) is shown in Figure 11 A for RGD peptidomimetic $\mathbf{1 0 .}$

Due to the absence of relevant long-range NOE contacts, several $10 \mathrm{~ns}$ runs of unconstrained MC/SD simulations were performed for high affinity ligand 28 (containing $\mathrm{N}$-1benzylated DKP-4, $3 R, 6 S$ ) starting from different 3D structures. Most of the conformations sampled during these simulations adopted an extended arrangement of the RGD sequence [C $\beta(\mathrm{Arg})-\mathrm{C} \beta(\mathrm{Asp})$ average distance of $8.8 \AA]$ and approximately $40 \%$ of them are characterized by a $\beta$-turn at Gly-Asp and the presence of the corresponding hydrogen bond between $\mathrm{DKP}-\mathrm{NH}_{10}$ and Arg- $\mathrm{C}=\mathrm{O}$. These results provide a structural model in agreement with NMR spectroscopy data showing a low temperature dependence 


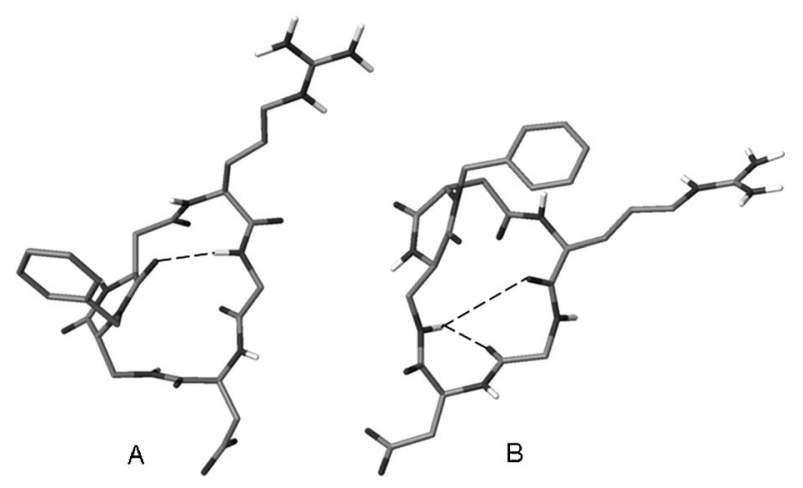

Figure 11. Structures of $\mathbf{1 0}$ and $\mathbf{2 8}$ as obtained by restrained MC/SD simulations based on experimental distance information, after energy minimization. A) Compound 10, type III H-bonding pattern, distorted inverse $\gamma$-turn at Asp and pseudo- $\beta$-turn at DKP-Arg $[\mathrm{C} \beta(\mathrm{Arg})-\mathrm{C} \beta(\mathrm{Asp})=$ $9.4 \AA$ ]. B) Compound 28, type I-trans $\mathrm{H}$-bonding pattern, inverse $\gamma$-turn at Asp and distorted $\beta \mathrm{II}^{\prime}$-turn at Gly-Asp $[\mathrm{C} \beta(\mathrm{Arg})-\mathrm{C} \beta(\mathrm{Asp})=9.0 \AA]$. Tube representation: $\mathrm{O}, \mathrm{N}$ in dark gray, $\mathrm{C}$ in light gray and $\mathrm{N}-\mathrm{H}$ hydrogen atoms in white; for the sake of clarity, all $\mathrm{H}$ atoms bound to carbon are omitted.

$\left(-0.7 \mathrm{ppbK}^{-1}\right)$ and an upfield chemical shift value $(\delta=$ $7.59 \mathrm{ppm}$ ) for proton $\mathrm{NH}_{10}$.

A representative energy minimized conformation selected by cluster analysis and featuring the $\mathrm{H}$ bond between DKP$\mathrm{NH}_{10}$ and $\mathrm{Arg}-\mathrm{C}=\mathrm{O}$ (type I-trans $\mathrm{H}$-bonding pattern) is shown in Figure 11B for RGD peptidomimetic 28. It is worth noting how the combination of the trans DKP-4 scaffold with the Gly-Asp $\beta$-turn occurs by generating an extended RGD arrangement, whereas the combination of the cis DKP-1 scaffold with the same secondary motif resulted in a non-extended RGD disposition (Figure 10 A). Accordingly, two type I H-bonding patterns have been defined (type I-cis and type I-trans), depending on the cis or trans relative stereochemistry of the diketopiperazine scaffold.

Three-dimensional structures satisfying long-range NOE contacts were generated for high affinity ligand $\mathbf{3 0}$ (containing $N$-1-benzylated DKP-6, $3 S, 6 R$ ) by performing two $10 \mathrm{~ns}$ restrained MC/SD simulations and applying the DKP-NH $\mathrm{N}_{10} /$ $\mathrm{NH}_{\text {Asp }}$ or the $\mathrm{NH}_{4} / \mathrm{NH}_{10}$ distance restraint derived from NOESY spectra (Table 2, Figure 8).

Most of the conformations sampled during the first simulation adopted an extended arrangement of the RGD sequence $[\mathrm{C} \beta(\mathrm{Arg})-\mathrm{C} \beta(\mathrm{Asp})$ average distance of $9.0 \AA]$ and approximately $40 \%$ of them are characterized by a $\beta$-turn at Gly-Asp and the corresponding hydrogen bond between $\mathrm{DKP}-\mathrm{NH}_{10}$ and $\mathrm{Arg}-\mathrm{C}=\mathrm{O}$. A representative energy minimized conformation selected by cluster analysis and featuring this $\mathrm{H}$ bond is shown in Figure $12 \mathrm{~A}$ (type I-trans $\mathrm{H}$ bonding pattern). Approximately $70 \%$ of the conformations sampled during the simulation of $\mathbf{3 0}$ featuring the $\mathrm{NH}_{4} / \mathrm{NH}_{10}$ distance restraint adopted an extended arrangement of the RGD sequence [C $\beta($ Arg $)-C \beta($ Asp) average distance of $8.8 \AA$ ] characterized by a pseudo- $\beta$-turn at AspDKP and the corresponding hydrogen bond between $\mathrm{NH}_{4}$ and Gly-C $=\mathrm{O}$. In addition, the formation of a $\gamma$-turn at Asp stabilized by the hydrogen bond between $\mathrm{NH}_{10}$ and Gly-

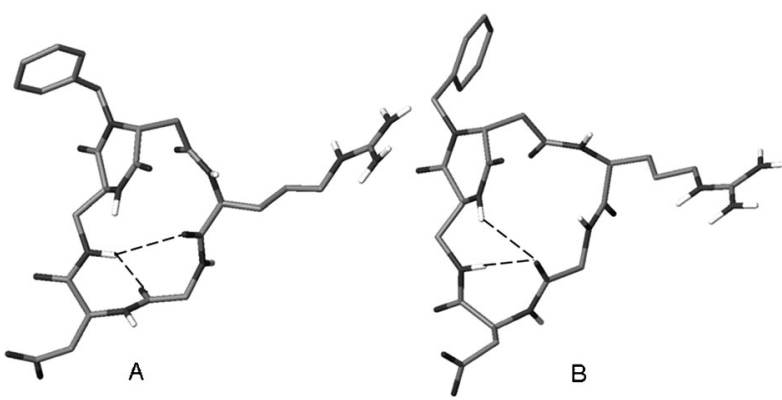

Figure 12. Structures of $\mathbf{3 0}$ as obtained by restrained MC/SD simulations based on experimental distance information, after energy minimization. A) Type I-trans H-bonding pattern, inverse $\gamma$-turn at Asp and distorted $\beta I^{\prime}$-turn at Gly-Asp $[\mathrm{C} \beta(\mathrm{Arg})-\mathrm{C} \beta(\mathrm{Asp})=9.0 \AA]$. B) Type IV H-bonding pattern, inverse $\gamma$-turn at Asp and pseudo- $\beta$-turn at Asp-DKP [C $\beta(A r g)-$ $\mathrm{C} \beta(\mathrm{Asp})=8.8 \AA$ ] . Tube representation: $\mathrm{O}, \mathrm{N}$ in dark gray, $\mathrm{C}$ in light gray and $\mathrm{N}-\mathrm{H}$ hydrogen atoms in white; for the sake of clarity, all $\mathrm{H}$ atoms bound to carbon are omitted.

$\mathrm{C}=\mathrm{O}$ was observed for $50 \%$ of the simulation. A representative energy minimized conformation selected by cluster analysis and featuring these $\mathrm{H}$ bonds is shown in Figure 12 B (type IV H-bonding pattern).

Three-dimensional structures satisfying long-range NOE contacts were generated for RGD peptidomimetic 31 (containing $N$-dibenzylated DKP-7, $3 S, 6 R$ ) by performing three $10 \mathrm{~ns}$ restrained MC/SD simulations and applying the following distance restraints derived from NOESY spectra of diastereoisomers $31 \mathrm{~A}$ and $31 \mathbf{B}$ (Table 2): in the first simulation a $\mathrm{NH}_{\mathrm{Arg}} / \mathrm{NH}_{\mathrm{Gly}}$ restraint, relevant in $\mathbf{3 1} \mathbf{A}$, in the second simulation a $\mathrm{NH}_{\mathrm{Asp}} / \mathrm{NH}_{\mathrm{Gly}}$ restraint, also relevant in $\mathbf{3 1} \mathbf{A}$, and in the third simulation a DKP-NH $10 / \mathrm{NH}_{\mathrm{Asp}}$ restraint, relevant in $\mathbf{3 1} \mathbf{B}$.

All the conformations sampled during the first two simulations adopted a non-extended arrangement of the RGD sequence $[C \beta(A r g)-C \beta(A s p)$ average distance of $6.6 \AA]$ characterized by the simultaneous presence of different turn motifs (pseudo- $\beta$-turn at DKP-Arg, $\gamma$-turn at Gly and pseudo- $\beta$-turn centered at the DKP unit). The structural models provided by these restrained MC/SD simulations differ from the conformations hypothesized on the basis of NMR spectroscopy data of $\mathbf{3 1} \mathbf{A}$ [equilibrium between type III (pseudo- $\beta$-turn at DKP-Arg) and type II ( $\beta$-turn at ArgGly) H-bonding patterns, see the NMR spectroscopy section]. However, also the calculated structures are able to provide an explanation for the NOE contacts and the NMR temperature coefficients observed for low affinity ligand $31 \mathbf{A}$.

The distance restraint corresponding to the NOE contact between DKP-NH $\mathrm{NH}_{10}$ and $\mathrm{NH}_{\text {Asp }}$ (observed in the NOESY spectrum of high affinity ligand 31B) was applied in the third $10 \mathrm{~ns}$ MC/SD simulation of compound 31. Most of the conformations sampled during this simulation adopted an extended arrangement of the RGD sequence $[C \beta(\mathrm{Arg})-\mathrm{C} \beta$ (Asp) average distance of $9.0 \AA$ ] and approximately $50 \%$ of them are characterized by a $\beta$-turn at Gly-Asp and the corresponding hydrogen bond between $\mathrm{DKP}-\mathrm{NH}_{10}$ and Arg$\mathrm{C}=\mathrm{O}$ (type I-trans $\mathrm{H}$-bonding pattern). 
Contrary to what was observed for the other cyclic RGD peptidomimetics containing DKP scaffolds, rotation of the DKP ring cannot be observed during the simulations performed on compound 31; this confirms $\mathbf{3 1} \mathbf{A}$ and $\mathbf{3 1} \mathbf{B}$ as two different separable conformers (diastereomers) due to hindered rotation of one ring around the other.

The distance restraint corresponding to the NOE contact between $\mathrm{NH}_{1}$ and $\mathrm{NH}_{\text {Arg }}$ was applied in the $10 \mathrm{~ns} \mathrm{MC} / \mathrm{SD}$ simulation of RGD peptidomimetic 32 (containing $N$-4-benzylated DKP-8, $3 S, 6 R$ ). Approximately $60 \%$ of the conformations sampled during this simulation adopted an extended arrangement of the RGD sequence characterized by the formation of the hydrogen bond between $\mathrm{NH}_{1}$ and Arg$\mathrm{C}=\mathrm{O}$ (Figure 9, type $\mathrm{V} \mathrm{H}$-bonding pattern). In addition, the formation of the hydrogen bond between $\mathrm{NH}_{\mathrm{Asp}}$ and $\mathrm{C}(2)=\mathrm{O}$ (type Va H-bonding pattern) or the presence of a $\beta$ turn at Gly-Asp stabilized by the hydrogen bond between DKP-NH $\mathrm{N}_{10}$ and $\mathrm{Arg}-\mathrm{C}=\mathrm{O}$ (type $\mathrm{Vb} \mathrm{H}$-bonding pattern) were observed for 35 and $25 \%$ of the simulation, respectively.

Representative energy minimized conformations selected by cluster analysis and featuring the type $\mathrm{Va}$ and $\mathrm{Vb} \mathrm{H}$ bonding patterns are shown in Figure 13 for RGD peptidomimetic 32.
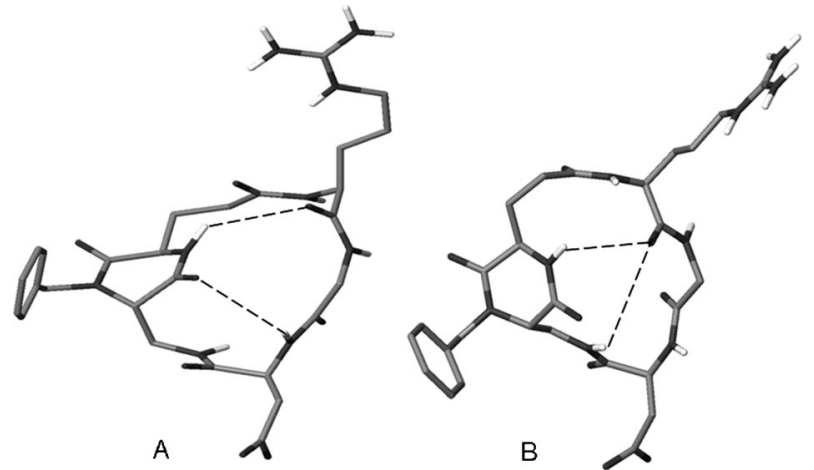

Figure 13. Structures of $\mathbf{3 2}$ as obtained by restrained MC/SD simulation based on experimental distance information, after energy minimization. A) Type Va H-bonding pattern $[C \beta(A r g)-C \beta(A s p)=9.9 \AA]$. B) Type $\mathrm{Vb}$ $\mathrm{H}$-bonding pattern $[\mathrm{C} \beta(\mathrm{Arg})-\mathrm{C} \beta(\mathrm{Asp})=9.1 \AA]$. Tube representation: O, $\mathrm{N}$ in dark gray, $\mathrm{C}$ in light gray and $\mathrm{N}-\mathrm{H}$ hydrogen atoms in white; for the sake of clarity, all $\mathrm{H}$ atoms bound to carbon are omitted.

Molecular docking: In order to rationalize, on a molecular basis, the affinity of cyclic RGD peptidomimetics for the $\alpha_{v} \beta_{3}$ receptor, docking studies were performed by starting from the representative conformations obtained from the $\mathrm{MC} / \mathrm{SD}$ simulations. The crystal structure of the extracellular segment of integrin $\alpha_{v} \beta_{3}$ complexed with the cyclic pentapeptide Cilengitide (PDB ID: 1L5G) was taken as a reference model for the interpretation of the docking results in terms of ligand-protein interactions. ${ }^{[5]}$ In the X-ray complex, Cilengitide binds to the interface of the $\alpha$ and $\beta$ units forming specific electrostatic interactions. The acid and basic pharmacophoric groups and their orientation are essential for binding to the $\alpha_{v} \beta_{3}$ because they act like an electrostatic clamp, interacting with charged regions of the receptor binding site.

Docking calculations starting from geometries featuring the type I-cis and type II H-bonding patterns produced topranked binding modes conserving optimal interactions only with the $\alpha$ subunit of the $\alpha_{v} \beta_{3}$ receptor. Probably, the short $\mathrm{C} \beta(\mathrm{Arg})-\mathrm{C} \beta(\mathrm{Asp})$ distances (values lower than $8 \AA$ ) of these geometries prevent the guanidine and carboxylic groups from achieving the required separation for binding to the $\alpha_{v} \beta_{3}$ integrin. On the other hand, docking calculations starting from the RGD extended conformations featuring the type I-trans, type III, type IV and type V H-bonding patterns $[\mathrm{C} \beta(\mathrm{Arg})-\mathrm{C} \beta(\mathrm{Asp})$ distance values $\geq 8.8 \AA]$ produced top-ranked binding modes conserving all the important interactions of the X-ray complex. As an example, the best pose obtained for the highest affinity ligand $\mathbf{3 1 B}$ featuring the type I-trans H-bonding pattern is shown in Figure 14.

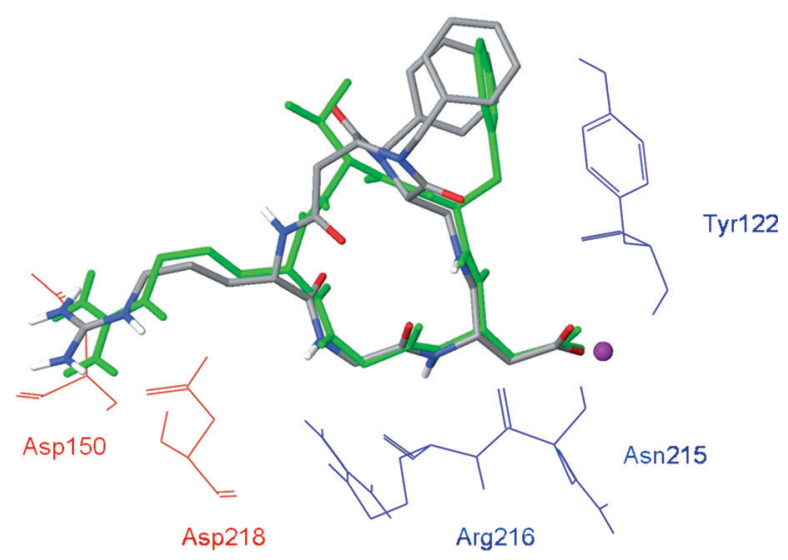

Figure 14. Docking best pose of compound 31 B (type I-trans H-bonding pattern, atom color tube representation) into the crystal structure of the extracellular domain of $\alpha_{v} \beta_{3}$ integrin ( $\alpha$ unit red and $\beta$ unit blue wire representation) overlaid on the bound conformation of Cilengitide (green tube representation). Only selected integrin residues involved in the interactions with the ligand are shown. The $\mathrm{Mn}^{2+}$ ion at MIDAS is shown as a magenta CPK sphere. For the sake of clarity, all $\mathrm{H}$ atoms bound to carbon are omitted.

The positively charged Arg guanidinium group of the ligand interacts with the negatively charged side chains of Asp218 and Asp150 in the $\alpha$ unit, one carboxylate oxygen of the ligand Asp side chain is coordinated to the metal cation in the metal-ion-dependent adhesion site (MIDAS) region of the $\beta$ unit, whereas the second carboxylate oxygen forms hydrogen bonds with the backbone amides of Asn215 and Tyr122 in the $\beta$ unit. Further stabilizing interaction involves the formation of a hydrogen bond between the ligand backbone $\mathrm{NH}$ of the Asp residue and the backbone carbonyl group of Arg216 in the $\beta$ unit. Favorable aromatic ring interactions between the ligand benzylic groups and the $\beta_{3}$ Tyr122 side chain could also be observed (Figure 14).

In light of all these considerations, the micromolar affinity of RGD peptidomimetics 9 and $\mathbf{3 1} \mathbf{A}$ (3.9 and $0.2 \mu \mathrm{M}$, respectively) for $\alpha_{v} \beta_{3}$ (Table 1) can be explained in terms of their 
low pre-organization for binding. In fact, as determined by the computational and NMR spectroscopy studies, in solution these compounds mainly feature non-extended RGD conformations, which according to the docking results, are not able to properly fit into the $\alpha_{v} \beta_{3}$ receptor. On the contrary, the nanomolar affinity of RGD peptidomimetics $\mathbf{1 0}$, 27-30, $31 \mathrm{~B}$ and 32 for $\alpha_{\mathrm{v}} \beta_{3}$ can be attributed to their high structural pre-organization. In fact, as determined by the computational and NMR spectroscopy studies, these compounds in solution mainly feature extended RGD conformations (principally determined by type I-trans, type III, type IV and type V H-bonding patterns) similar to the RGD bound conformation of Cilengitide.

\section{Conclusion}

In summary, we have synthesized a small library of bifunctional diketopiperazine (DKP) scaffolds, which were formally derived from 2,3-diaminopropionic acid and aspartic acid (DKP-1-DKP-7) or glutamic acid (DKP-8) and feature an amine and a carboxylic acid functional group. The scaffolds differ for the configuration at the two stereocenters and the substitution at the diketopiperazinic nitrogen atoms. The bifunctional diketopiperazines were introduced into eight cyclic peptidomimetics containing the Arg-Gly-Asp (RGD) sequence. The resulting RGD peptidomimetics were screened for their ability to inhibit biotinylated vitronectin binding to the purified integrins $\alpha_{\mathrm{v}} \beta_{3}$ and $\alpha_{\mathrm{v}} \beta_{5}$, which are involved in tumor angiogenesis. Nanomolar values were obtained for the RGD peptidomimetics derived from trans DKP scaffolds (DKP-2-DKP-8). Conformational studies of the cyclic RGD peptidomimetics by ${ }^{1} \mathrm{H}$ NMR spectroscopy experiments (VT-NMR and NOESY) in aqueous solution and Monte Carlo/Stochastic Dynamics (MC/SD) simulations revealed that the highest affinity ligands display well-defined preferred conformations featuring intramolecular hydrogen-bonded turn motifs and an extended arrangement of the RGD sequence $[C \beta(A r g)-C \beta(A s p)$ average distance $\geq 8.8 \AA]$. Docking studies were performed, starting from the representative conformations obtained from the MC/SD simulations and taking as a reference model the crystal structure of the extracellular segment of integrin $\alpha_{v} \beta_{3}$ complexed with the cyclic pentapeptide, Cilengitide. The highest affinity ligands produced top-ranked poses conserving all the important interactions of the X-ray complex.

\section{Experimental Section}

A detailed procedure for the synthesis of intermediate $\mathbf{1 5}$ starting from protected amino acid derivatives $\mathbf{1 1}$ and $\mathbf{1 2}$ was already reported. ${ }^{[16]}$ The same procedure was used for the synthesis of intermediate 20, starting from protected amino acid derivatives 18 and 12. Diketopiperazine 26 ring closure was achieved under similar conditions by using $\mathrm{Et}_{3} \mathrm{SiH}$ (2.5 equiv) as a scavenger during Boc cleavage.

General procedure for the synthesis of diketopiperazine azides: $\mathrm{PPh}_{3}$ (1.5 equiv) was added to a solution of diketopiperazines $\mathbf{1 5}$ or $\mathbf{2 0}$
( 1 equiv) in $\mathrm{CH}_{2} \mathrm{Cl}_{2}$ /toluene (2:1) under a nitrogen atmosphere and at $-20^{\circ} \mathrm{C}$, and the mixture was stirred until a solution was obtained. Hydrazoic acid (1.5 $\mathrm{M}$ in toluene, 3 equiv) was added followed by dropwise addition of DIAD (1.5 equiv) and the reaction was stirred at $-20^{\circ} \mathrm{C}$ for $3-$ $16 \mathrm{~h}$. The reaction mixture was loaded onto a silica gel column and purified by flash chromatography (for solvents and ratios used, see the Supporting Information) to afford the desired product as a white foam (69$86 \%)$.

General procedure for the synthesis of dipeptide 25: DCC (1 equiv) was added to a solution of either $(R)$ - or $(S)-N$-Boc-Ser $\left(\mathrm{N}_{3}\right)-\mathrm{OH}(\mathbf{2 3} ; 2$ equiv) in $\mathrm{CH}_{2} \mathrm{Cl}_{2}$, in one portion. A white precipitate (DCU) formed and stirring was continued for $1 \mathrm{~h}$ at room temperature. The mixture was then filtered on cotton wool to remove DCU. The white DCU residue was washed twice with cold $\mathrm{CH}_{2} \mathrm{Cl}_{2}$. The filtrate was concentrated under reduced pressure at room temperature, and dried under high vacuum to afford symmetric anhydride $\mathbf{2 4}$ as a pale yellow foam, which was used without further purification. Either $(R)$ - or $(S)$ - $N$-benzyl-aspartic acid dimethylester ( 0.7 equiv) was dissolved in $\mathrm{CH}_{2} \mathrm{Cl}_{2}$ and the mixture was cooled to $0{ }^{\circ} \mathrm{C}$. A solution of symmetric anhydride in $\mathrm{CH}_{2} \mathrm{Cl}_{2}$ was then added dropwise (very slowly). The reaction mixture was allowed to reach room temperature and was stirred at room temperature, overnight. The solvent was then removed under reduced pressure and the residue was purified by flash chromatography (hexane/EtOAc 8:2) on silica gel to afford the desired product as a viscous transparent oil $(80 \%)$.

General diketopiperazine $\boldsymbol{N}$-benzylation procedure: A flame-dried flask under $\mathrm{N}_{2}$ was charged with a solution of $\mathbf{2 6}$ (1 equiv) in dry THF. The temperature was lowered to $-78^{\circ} \mathrm{C}$ and KHMDS ( $0.5 \mathrm{~m}$ solution in toluene, 1.1 equiv) was added dropwise. After $30 \mathrm{~min}$ benzyl bromide (5 equiv) was added, and a final solvent ratio THF/DMF 7:3 was reached by adding DMF. The mixture was allowed to reach $-40^{\circ} \mathrm{C}$ and stirred for $3 \mathrm{~h}$. Then aqueous $\mathrm{NH}_{4} \mathrm{Cl}$ was slowly added and the mixture was extracted with EtOAc $(3 \times)$. The organic phases were then washed with brine and dried over $\mathrm{Na}_{2} \mathrm{SO}_{4}$. Volatiles were removed under reduced pressure and the residue was purified by flash chromatography on silica gel to afford the desired product as a viscous transparent oil $(86 \%)$.

General procedure for diketopiperazine azide reduction and Boc protection: A) 2-(tert-Butoxycarbonyloxyimino)-2-phenylacetonitrile (Boc-ON, 2.2 equiv) and $\mathrm{Me}_{3} \mathrm{P}$ ( $1 \mathrm{M}$ solution in toluene, 2 equiv) were added successively to a solution of diketopiperazine azide (1 equiv) in THF, under a nitrogen atmosphere and at $-20^{\circ} \mathrm{C}$. After being stirred for $6 \mathrm{~h}$ at room temperature, the solution was diluted with $\mathrm{CH}_{2} \mathrm{Cl}_{2}$ and washed with $\mathrm{H}_{2} \mathrm{O}$ $(3 \times)$ and brine. The organic phase was dried over $\mathrm{Na}_{2} \mathrm{SO}_{4}$ and volatiles were removed under reduced pressure. The residue was purified by flash chromatography (for solvents and ratios used, see the Supporting Information) on silica gel to afford the desired product as a white foam (76$87 \%)$.

B) Diketopiperazine azide (1 equiv) was dissolved in THF and $\mathrm{Pd} / \mathrm{C}$ ( 0.1 equiv) was added. The flask was thoroughly purged with $\mathrm{H}_{2}$, and the system was closed. The reaction mixture was stirred at room temperature for $4 \mathrm{~h}$, and then filtered through a Celite pad. The cake thus obtained was thoroughly washed with THF. The filtrate was concentrated and dried to give the crude product as a transparent paste $(95 \%)$, which was dissolved in THF $(35 \mathrm{~mL})$. $\mathrm{Boc}_{2} \mathrm{O}$ (1.1 equiv) was then added in one portion. After stirring the mixture at room temperature, overnight, EtOAc was added. The solution was washed with $\mathrm{KHSO}_{4}(1 \mathrm{M} ; 4 \times)$ and brine $(1 \times)$. The organic phase was dried over $\mathrm{Na}_{2} \mathrm{SO}_{4}$ and volatiles were removed under reduced pressure, to afford the desired product as a white foam $(95 \%)$, which was used without further purification.

General procedure for diketopiperazine allyl ester deprotection: Diketopiperazine allyl ester ( 1 equiv) was dissolved in $\mathrm{CH}_{2} \mathrm{Cl}_{2}$ under a nitrogen atmosphere. After cooling the solution at $0^{\circ} \mathrm{C}$, pyrrolidine (1.2 equiv), $\mathrm{PPh}_{3}$ (0.18 equiv) and $\left[\mathrm{Pd}\left(\mathrm{PPh}_{3}\right)_{4}\right](0.04$ equiv) were added successively. After being stirred for $1 \mathrm{~h}$ at $0^{\circ} \mathrm{C}$, the mixture was diluted with EtOAc and extracted with aqueous $\mathrm{NaHCO}_{3}(4 \times)$. The combined aqueous phases were acidified to $\mathrm{pH} 2$ with a $\mathrm{KHSO}_{4}(1 \mathrm{M})$ solution and then extracted with $\mathrm{CH}_{2} \mathrm{Cl}_{2}$. The resulting organic phase was dried over $\mathrm{Na}_{2} \mathrm{SO}_{4}$ and the solvent was evaporated to afford the desired product as a fluffy white solid (99\%). 
Procedure for diketopiperazine methyl ester hydrolysis: A) Diketopiperazine methyl ester ( 1 equiv) was dissolved in THF and the mixture was cooled to $0^{\circ} \mathrm{C}$. A solution of $\mathrm{LiOH} \cdot \mathrm{H}_{2} \mathrm{O}$ (2.5 equiv) in $\mathrm{H}_{2} \mathrm{O}$ was added dropwise. The resulting solution was stirred for $1 \mathrm{~h}$ at $0^{\circ} \mathrm{C}$. Then, maintaining the temperature at $0^{\circ} \mathrm{C}$, the mixture was acidified with $\mathrm{HCl}(1 \mathrm{M})$ to $\mathrm{pH} 1-2$, and extracted with $\mathrm{CH}_{2} \mathrm{Cl}_{2}(4 \times)$. The collected organic phases were dried over $\mathrm{Na}_{2} \mathrm{SO}_{4}$ and volatiles were removed under reduced pressure. Either DKP-4 or DKP-6 were afforded as a white foam (100\%). B) Diketopiperazine methyl ester (1 equiv) was dissolved in THF. The mixture was cooled to $0^{\circ} \mathrm{C}$ and a solution of $\mathrm{LiOH}(2.7 \mathrm{M})$ in $\mathrm{H}_{2} \mathrm{O}_{2}(35 \%$ $\mathrm{v} / \mathrm{v})$ was added dropwise. The mixture was stirred for an additional $30 \mathrm{~min}$ at $0^{\circ} \mathrm{C}$, then warmed to room temperature and stirred for $7 \mathrm{~h}$. After addition of $\mathrm{Na}_{2} \mathrm{SO}_{3}$ (6 equiv) the reaction mixture was diluted with $\mathrm{THF} / \mathrm{H}_{2} \mathrm{O}$ (1:1). $\mathrm{KHSO}_{4}(1 \mathrm{~m})$ was then added until $\mathrm{pH} 1-2$ was reached, and the mixture was extracted with DCM $(4 \times)$. The collected organic phases were dried over $\mathrm{Na}_{2} \mathrm{SO}_{4}$ and volatiles removed under reduced pressure, to afford crude DKP-8 as a yellowish solid. The crude product was dissolved in EtOAc and extracted with a saturated $\mathrm{NaHCO}_{3}$ aqueous solution; collected aqueous layers were acidified with $\mathrm{KHSO}_{4}(1 \mathrm{M})$ to reach $\mathrm{pH} 1-2$, and extracted with DCM $(4 \times)$. Collected organic phases were dried over $\mathrm{Na}_{2} \mathrm{SO}_{4}$ and volatiles were removed under reduced pressure, to afford DKP-8 as a white foam (90\%).

General procedure for Boc deprotection reactions: A half volume of TFA was added to a solution of the $N$-Boc-protected amino acid or peptide in $\mathrm{CH}_{2} \mathrm{Cl}_{2}(0.13 \mathrm{M})$. The reaction mixture was stirred for $2 \mathrm{~h}$ at room temperature and then concentrated at reduced pressure. Excess TFA was azeotropically removed from the residue with toluene. Diethyl ether was added to the residue and the resulting suspension was evaporated under reduced pressure to afford the corresponding TFA salt.

General procedure for coupling reactions: HATU (1.2 equiv), HOAt (1.2 equiv) and DIPEA (4 equiv) were added successively to a solution of the N-protected amino acid in DMF, under a nitrogen atmosphere and at $0^{\circ} \mathrm{C}$. After $30 \mathrm{~min}$, a solution of the $\mathrm{N}$-deprotected TFA salt of the peptide in DMF was added and the reaction mixture was stirred at $0^{\circ} \mathrm{C}$ for $1 \mathrm{~h}$ and at room temperature, overnight. The mixture was then diluted with EtOAc and consecutively washed with $\mathrm{KHSO}_{4}(1 \mathrm{M} ; 2 \times)$, a saturated $\mathrm{NaHCO}_{3}$ aqueous solution $(2 \times)$, brine $(2 \times)$, and dried over $\mathrm{Na}_{2} \mathrm{SO}_{4}$. Volatiles were evaporated under reduced pressure to afford the crude product.

General procedure for $\mathbf{C b z}$ and $\mathrm{OBn}$ hydrogenolytic cleavage: Protected compound (1 equiv) was dissolved in a mixture of $\mathrm{THF} / \mathrm{H}_{2} \mathrm{O}(1: 1)$ and $\mathrm{Pd} / \mathrm{C} 10 \%$ ( 0.1 equiv) was added. The reaction mixtures were subjected to three vacuum/hydrogen cycles and then stirred, overnight, at room temperature under 1 bar of hydrogen. The mixture was filtered through Celite, and the cake thus obtained was washed thoroughly with THF/ $\mathrm{H}_{2} \mathrm{O}$ (1:1). The filtrate was concentrated and dried to give the crude product as white solid (100\%).

General procedure for macrolactamization: HATU (4 equiv), HOAt (4 equiv) and DIPEA (6 equiv) were added successively to a solution of deprotected linear compound (1.4 mM; 1 equiv) in DMF, under a nitrogen atmosphere at $0^{\circ} \mathrm{C}$. After stirring the reaction mixture at $0^{\circ} \mathrm{C}$ for $1 \mathrm{~h}$, it was allowed to reach room temperature and stirred, overnight. DMF was then removed under reduced pressure and the residue was purified by flash chromatography $\left(\mathrm{CH}_{2} \mathrm{Cl}_{2} / \mathrm{MeOH}\right.$; for ratios used, see the Supporting Information) on silica gel to afford the product as white foam (31$74 \%)$.

Solid-phase receptor-binding assay: Purified $\alpha_{\mathrm{v}} \beta_{3}$ and $\alpha_{\mathrm{v}} \beta_{5}$ receptors (Chemicon International, Inc., Temecula, CA) were diluted to $0.5 \mu \mathrm{g} \mathrm{mL}^{-1}$ in coating buffer containing Tris- $\mathrm{HCl}\left(20 \mathrm{mmolL}^{-1} ; \mathrm{pH} 7.4\right)$, $\mathrm{NaCl}\left(150 \mathrm{mmolL}^{-1}\right), \mathrm{MnCl}_{2}\left(1 \mathrm{mmolL}^{-1}\right), \mathrm{CaCl}_{2}\left(2 \mathrm{mmolL}^{-1}\right)$ and $\mathrm{MgCl}_{2}\left(1 \mathrm{mmolL}^{-1}\right)$. An aliquot of diluted receptors $(100 \mu \mathrm{L}$ per well $)$ was added to 96-well microtiter plates (Nunc MW 96F Medisorp Straight) and incubated, overnight, at $4^{\circ} \mathrm{C}$. The plates were then incubated with blocking solution (coating buffer plus $1 \%$ bovine serum albumin) for an additional $2 \mathrm{~h}$ at room temperature to block nonspecific binding followed by $3 \mathrm{~h}$ incubation at room temperature with various concentrations $\left(10^{-12}-10^{-5} \mathrm{M}\right)$ of test compounds in the presence of vitronectine $\left(1 \mu \mathrm{gLL}^{-1}\right)$ biotinylated by using EZ-Link Sulfo-NHS-Biotinylation kit
(Pierce, Rockford, IL). After washing, the plates were incubated for $1 \mathrm{~h}$ at room temperature with streptavidin-biotinylated peroxidase complex (Amersham Biosciences, Uppsala, Sweden) followed by $30 \mathrm{~min}$ incubation with substrate reagent solution $(100 \mu \mathrm{L} ; \mathrm{R} \& \mathrm{D}$ Systems, Minneapolis, $\mathrm{MN})$ before stopping the reaction by addition of $\mathrm{H}_{2} \mathrm{SO}_{4}(2 \mathrm{~N}, 50 \mu \mathrm{L})$. Absorbance at $415 \mathrm{~nm}$ was read in a Synergy ${ }^{\mathrm{TM}} \mathrm{HT}$ multi-detection microplate reader (BioTek Instruments, Inc.). Each data point is the result of the average of triplicate wells and was analyzed by nonlinear regression analysis with Prism GraphPad program. Each experiment was repeated in triplicate.

General procedure for Mtr and OtBu ester removal: Protected macrolactams were treated with TFA $(0.01 \mathrm{M})$ in the presence of ion scavengers: thioanisole ( $5 \%)$, ethanedithiol (3\%), anisole $(2 \%)$. After TFA removal, under reduced pressure, the residue was dissolved in a 1:1 mixture of diisopropyl ether/water. Phases were separated and the aqueous layer was washed several times with diisopropyl ether. The aqueous phase was concentrated under reduced pressure to give the crude product, which was purified by HPLC to give the desired compound as white solid (60$80 \%)$.

NMR spectroscopy studies: NMR spectroscopy experiments were performed at a temperature of $298 \mathrm{~K}$ on Bruker Avance 400 and $600 \mathrm{MHz}$ spectrometers. All proton and carbon chemical shifts were assigned unambiguously. The NMR experiments were carried out in a $\mathrm{D}_{2} \mathrm{O} / \mathrm{H}_{2} \mathrm{O}$ 1:9 mixture in order to observe amide protons. Two-dimensional experiments (TOCSY, NOESY, and HSQC) were carried out on samples of cyclic RGD peptidomimetics $9, \mathbf{1 0}, \mathbf{2 7}-\mathbf{3 2}$ at a concentration range of 3-6 mM. NOESY experiments were performed at 0.7 or $0.8 \mathrm{~s}$. The water resonance was saturated with the excitation sculpting sequence from the Bruker library. The conformations of the cyclic pentapeptides were analyzed with respect to hydrogen bonding of amide protons (VT-NMR spectroscopy) and NOE contacts.

Computational studies: All calculations were run by using the Schrödinger suite of programs (http://www.schrodinger.com) through the Maestro graphical interface.

Conformational analysis: Conformational preferences of the RGD peptidomimetics were investigated by Monte Carlo/Stochastic Dynamics (MC SD) hybrid simulations ${ }^{[32]}$ by using the NMR spectroscopy restraints derived from the experimental NOE contacts (for distance restraints used for each calculation, see the Supporting Information). All the NOE restraints were set to a distance value of $2( \pm 0.5) \AA$ with a force constant of $100 \mathrm{~kJ} \mathrm{~mol}^{-1} \AA^{-2}$. MC/SD simulations were performed at $300 \mathrm{~K}$ within the framework of MacroModel version $9.5^{[36]}$ by employing the OPLS_2001 force field ${ }^{[34]}$ and the implicit water GB/SA solvation model. ${ }^{[33]}$ RGD side-chain dihedral angles were defined as internal coordinate degrees of freedom in the Monte Carlo part of the algorithm. A time step of $1 \mathrm{fs}$ was used for the stochastic dynamics (SD) part of the algorithm for $10 \mathrm{~ns}$ of simulation time. Samples were taken at 2 ps intervals during each simulation, yielding 5000 conformations for analysis. The percentages of $\mathrm{H}$ bonds discussed here were calculated as percentages of conformations sampled during the simulation in which donor $\mathrm{H}$-acceptor $\mathrm{O}$ distance $<2.5 \AA$ ( $\gamma$-turn) or $<4 \AA$ ( $\beta$-turn).

Molecular docking: The recently solved crystal structure of the extracellular domain of the integrin $\alpha_{\mathrm{v}} \beta_{3}$ receptor in complex with Cilengitide and in the presence of the proadhesive ion $\mathrm{Mn}^{2+}$ (PDB ID: $\left.1 \mathrm{L5G}\right)^{[5]}$ was used for docking studies. Docking was performed only on the globular head of the integrin because the headgroup of integrin has been identified in the X-ray structure as the ligand-binding region. The protein structure was setup for docking as follows. The protein was truncated to residue sequences $41-342$ for chain $\alpha$ and 114-347 for chain $\beta$. Due to a lack of parameters, the $\mathrm{Mn}^{2+}$ ions in the experimental protein structure were modeled by replacing them with $\mathrm{Ca}^{2+}$ ions. The resulting structure was prepared by using the Protein Preparation Wizard of the graphical user interface Maestro and the OPLSAA force field. The automated docking calculations were performed by using Glide ${ }^{[37]}$ (Grid-based Ligand Docking with Energetics). The grid generation step started from the extracellular fragment of X-ray structure of $\alpha_{v} \beta_{3}$ complex with Cilengitide, as described in the protein setup section. The center of the grid enclosing box was defined by the center of the bound ligand, as described 
in the original PDB entry. The enclosing box dimensions, which are automatically deduced from the ligand size, fit the entire active site. For the docking step, the size of the bounding box for placing the ligand center was set to $12 \AA$. No further modifications were applied to the default settings. The GlideScore function was used to select 20 poses for each ligand. The Glide program was initially tested for its ability to reproduce the crystallized binding geometry of Cilengitide. The program was successful in reproducing the experimentally determined binding mode of this compound, as it corresponds to the best-scored pose.

\section{Acknowledgements}

We thank Milan University for PhD Fellowships (to M.M., M.M., R.C. and I.G.). We also gratefully acknowledge Ministero dell'Università e della Ricerca for financial support (PRIN prot. 2008J4YNJY). U.P. thanks Fondazione CARIPLO for a research grant (Project: RedDrugTrain).

[1] R. O. Hynes, Cell 2002, 110, 673-687.

[2] M. Shimaoka, T. A. Springer, Nat. Rev. Drug Discovery 2003, 2, $703-716$.

[3] P. C. Brooks, A. M. Montgomery, M. Rosenfeld, R. A. Reisfeld, T. Hu, G. Klier, D. A. Cheresh, Cell 1994, 79, 1157-1164.

[4] E. F. Plow, T. A. Haas, L. Zhang, J. Loftus, J. W. Smith, J. Biol. Chem. 2000, 275, 21785-21788.

[5] J.-P. Xiong, T. Stehle, R. Zhang, A. Joachimiak, M. Frech, S. L. Goodman, M. A. Arnaout, Science 2002, 296, 151-155.

[6] M. A. Dechantsreiter, E. Planker, B. Mathä, E. Lohof, G. Hölzemann, A. Jonczyk, S. L. Goodman, H. Kessler, J. Med. Chem. 1999, 42, 3033-3040.

[7] K.-E. Gottschalk, H. Kessler, Angew. Chem. 2002, 114, 3919-3927; Angew. Chem. Int. Ed. 2002, 41, 3767-3774.

[8] C. Mas-Moruno, F. Rechenmacher, H. Kessler, Anti-Cancer Agents Med. Chem. 2010, 10, 753-768.

[9] L. Auzzas, F. Zanardi, L. Battistini, P. Burreddu, P. Carta, G. Rassu, C. Curti, G. Casiraghi, Curr. Med. Chem. 2010, 17, 1255-1299.

[10] a) G. Casiraghi, G. Rassu, L. Auzzas, P. Bureddu, E. Gaetani, L. Battistini, F. Zanardi, C. Curti, G. Nicastro, L. Belvisi, I. Motto, M. Castorina, G. Giannini, C. Pisano, J. Med. Chem. 2005, 48, 76757687; b) F. Zanardi, P. Bureddu, G. Rassu, L. Auzzas, L. Battistini, C. Curti, A. Sartori, G. Nicastro, G. Menchi, N. Cini, A. Bottonocetti, S. Raspanti, G. Casiraghi, C. Pisano, J. Med. Chem. 2008, 51, $1771-1782$.

[11] a) L. Belvisi, T. Riccioni, M. Marcellini, I. Chiarucci, D. Efrati, L. Vesci, D. Potenza, C. Scolastico, L. Manzoni, K. Lombardo, M. A. Stasi, B. Nico, D. Ribatti, M. Presta, P. Carminati, C. Pisano, Mol. Cancer Ther. 2005, 4, 1670-1680; b) L. Belvisi, A. Bernardi, M. Colombo, L. Manzoni, D. Potenza, C. Scolastico, G. Giannini, M. Marcellini, T. Riccioni, M. Castorina, P. LoGiudice, C. Pisano, Bioorg. Med. Chem. 2006, 14, 169-180; c) L. Manzoni, L. Belvisi, D. Arosio, M. Civera, M. Pilkington-Miksa, D. Potenza, A. Caprini, E. M. V. Araldi, E. Monferrini, M. Mancino, F. Podestà, C. Scolastico, ChemMedChem 2009, 4, 615-632.

[12] F. Schumann, A. Müller, M. Koksch, G. Müller, N. Sewald, J. Am. Chem. Soc. 2000, 122, 12009-12010.

[13] S. Urman, K. Gaus, Y. Yang, U. Strijowski, N. Sewald, S. De Pol, O. Reiser, Angew. Chem. 2007, 119, 4050-4053; Angew. Chem. Int. Ed. 2007, 46, 3976-3978.
[14] D. Heckmann, A. Meyer, L. Marinelli, G. Zahn, R. Stragies, H Kessler, Angew. Chem. 2007, 119, 3641-3644; Angew. Chem. Int. Ed. 2007, 46, 3571-3574, and references therein.

[15] A. S. M. Ressurreição, A. Bordessa, M. Civera, L. Belvisi, C. Gennari, U. Piarulli, J. Org. Chem. 2008, 73, 652-660.

[16] A. S. M. Ressurreicao, A. Vidu, M. Civera, L. Belvisi, D. Potenza, L. Manzoni, S. Ongeri, C. Gennari, U. Piarulli, Chem. Eur. J. 2009, 15, $12184-12188$

[17] M. Marchini, M. Mingozzi, R. Colombo, C. Gennari, M. Durini, U. Piarulli, Tetrahedron 2010, 66, 9528.

[18] K. L. Webster, A. B. Maude, M. E. O'Donnell, A. P. Mehrotra, D. J. Gani, Chem. Soc. Perkin Trans. 1 2001, 1673-1695.

[19] C. M. Thompson, J. A. Frick, D. L. C. Green, J. Org. Chem. 1990, 55, $111-116$.

[20] This procedure has been reported for the successful synthesis of 2,3diamino propionic acid starting from serine derivatives, see: a) $\mathrm{S}$. H Rosenberg, K. P. Spina, K. W. Woods, J. Polakowski, D. L. Martin, Z. Yao, H. H. Stein, J. Cohen, J. L. Barlow, J. Med. Chem. 1993, 36, 449-459; b) I. F. Pickersgill, H. Rapoport, J. Org. Chem. 2000, 65, $4048-4057$.

[21] X. Ariza, F. Urpí, C. Viladomat, J. Vilarrasa, Tetrahedron Lett. 1998 39, 9101-9102.

[22] C. David, L. Bischoff, H. Meudal, A. Mothé, N. De Mota, S. DaNascimento, C. Llorens-Cortes, M.-C. Fournié-Zaluski, B. P. Roques, $J$. Med. Chem. 1999, 42, 5197-5211.

[23] V. Bavetsias, A. L. Jackman, R. Kimbell, W. Gibson, F. T. Boyle, G. M. F. Bisset, J. Med. Chem. 1996, 39, 73-85.

[24] J. M. Humphrey, R. J. Bridges, J. A. Hart, A. R. Chamberlin, J. Org. Chem. 1994, 59, 2467-2472.

[25] L. A. Carpino, A. El-Faham, F. Albericio, J. Org. Chem. 1995, 60, 3561-3564.

[26] J. Coste, E. Frérot, P. Jouin, J. Org. Chem. 1994, 59, 2437-2446.

[27] T. Shioiri, K. Ninomiya, S. Yamada, J. Am. Chem. Soc. 1972, 94, $6203-6205$.

[28] Y. Fu, R. P. Hammer, Org. Lett. 2002, 4, 237-240

[29] J.-M. Luo, C.-F. Dai, S.-Y. Lin, P.-Q. Huang, Chem. Asian J. 2009, 4, $328-335$.

[30] M. De Greef, S. Abeln, K. Belkhasmi, A. Dömling, R. V. A. Orru, L. A. Wessjohann, Synthesis 2006, 3997-4004.

[31] a) G. Müller, M. Gurrath, H. Kessler, J. Comput.-Aided Mol. Des. 1994, 8, 709-730; b) R. Haubner, R. Gratias, B. Diefenbach, S. L. Goodman, A. Jonczyk, H. Kessler, J. Am. Chem. Soc. 1996, 118, 7461-7472; c) R. Haubner, W. Schmitt, G. Hölzemann, S. L. Goodman, A. Jonczyk, H. Kessler, J. Am. Chem. Soc. 1996, 118, 7881 7891.

[32] F. Guarnieri, W. C. Still, J. Comput. Chem. 1994, 15, 1302-1310.

[33] W. C. Still, A. Tempczyk, R. C. Hawley, T. Hendrickson, J. Am. Chem. Soc. 1990, 112, 6127-6129.

[34] W. L. Jorgensen, D. S. Maxwell, J. Tirado-Rives, J. Am. Chem. Soc 1996, 118, 11225-11236.

[35] The OPLS_2001 force field, among several commonly used force fields, provided the highest correlation between calculated and experimental conformational preferences within the series of cyclic RGD peptidomimetics containing diketopiperazine scaffolds with different stereochemistry and substitution at the piperazinic nitrogen atoms.

[36] MacroModel, version 9.5, Schrödinger, LLC, New York, 2007.

[37] Glide, version 4.5, Schrödinger, LLC, New York, 2007.

Received: February 12, 2012 Published online: April 19, 2012 